\title{
Growth of ice particle mass and projected area during riming
}

\author{
Ehsan Erfani ${ }^{1,2, a}$ and David L. Mitchell ${ }^{1}$ \\ ${ }^{1}$ Desert Research Institute, Reno, Nevada, USA \\ ${ }^{2}$ Graduate Program in Atmospheric Sciences, University of Nevada, Reno, Nevada, USA \\ anow at: Center for Ocean-Land-Atmosphere studies, George Mason University, Fairfax, Virginia, USA
}

Correspondence to: Ehsan Erfani (eerfani@gmu.edu)

Received: 27 May 2016 - Published in Atmos. Chem. Phys. Discuss.: 7 June 2016

Revised: 11 December 2016 - Accepted: 9 January 2017 - Published: 27 January 2017

\begin{abstract}
There is a long-standing challenge in cloud and climate models to simulate the process of ice particle riming realistically, partly due to the unrealistic parameterization of the growth of ice particle mass $(m)$ and projected area $(A)$ during riming. This study addresses this problem, utilizing ground-based measurements of $m$ and ice particle maximum dimension $(D)$ as well as theory to formulate simple expressions describing the dependence of $m$ and $A$ on riming. It was observed that $\beta$ in the $m-D$ power law $m=\alpha D^{\beta}$ appears independent of riming during the phase 1 (before the formation of graupel), with $\alpha$ accounting for the ice particle mass increase due to riming. This semi-empirical approach accounts for the degree of riming and renders a gradual and smooth ice particle growth process from unrimed ice particles to graupel, and thus avoids discontinuities in $m$ and $A$ during accretional growth. Once the graupel with quasispherical shape forms, $D$ increases with an increase in $m$ and $A$ (phase 2 of riming). The treatment for riming is explicit, and includes the parameterization of the ice crystal-cloud droplet collision efficiency $\left(E_{\mathrm{c}}\right)$ for hexagonal columns and plates using hydrodynamic theory. In particular, $E_{\mathrm{c}}$ for cloud droplet diameters less than $10 \mu \mathrm{m}$ are estimated, and under some conditions observed in mixed-phase clouds, these droplets can account for roughly half of the mass growth rate from riming. These physically meaningful yet simple methods can be used in models to improve the riming process.
\end{abstract}

\section{Introduction}

Observational studies have determined that the riming process contributes substantially to snowfall rates. Along the coastal plains of northern Japan, riming was responsible for 50 to $\sim 100 \%$ of the mass of snow collected at ground level, which included graupel particles (Harimaya and Sato, 1989). When only snowflakes were considered (no graupel), riming contributed between 40 and $63 \%$ of the snow mass. In the Colorado Rocky Mountains, Feng and Grant (1982) found that, for the same number flux, the snowfall rate for rimed plates and dendrites was about twice the snowfall rate for unrimed plates and dendrites (implying that about half of the snowfall rate was due to riming). In the Sierra Nevada of California, Mitchell et al. (1990; hereafter M90) estimated that riming contributed 30 to $40 \%$ of the mass of fresh snow during two snowfall events. Thus, an improved treatment of the riming process in cloud-resolving models could significantly improve predicted snowfall amounts. This could also translate to improved quantitative precipitation estimates (QPEs) from National Weather Service (NWS) radar systems during winter. For example, a simple snow growth model can be coupled with National Weather Service radar reflectivity as described in Mitchell et al. (2006) to improve QPE, and adding the riming process should further improve these QPEs during winter storms.

The life cycle of Arctic mixed-phase clouds, which strongly affect the Arctic energy budget and climate, should be affected by the mass sink, represented by the ice mass flux $\left(M_{\mathrm{f}}\right.$; all symbols are defined at the end of the manuscript) at cloud base (representing a moisture sink). Riming has a strong impact on ice particle fall speeds (Mitchell, 1996; hereafter M96), and $M_{\mathrm{f}}$ can be estimated as $M_{\mathrm{f}}=\mathrm{IWC} \times V_{\mathrm{m}}$, 
where $V_{\mathrm{m}}$ is the mass-weighted fall speed at cloud base and IWC is the ice water content. Since riming strongly contributes to both IWC and $V_{\mathrm{m}}$, it has a considerable impact on $M_{\mathrm{f}}$.

\subsection{Characteristics of riming}

Riming (accretion of supercooled water droplets on ice particles) occurs in mixed-phase clouds where ice particles and water droplets coexist at temperatures $(T)$ between -37.5 and $0{ }^{\circ} \mathrm{C}$ in convective clouds in the tropics (Rosenfeld and Woodley, 2000; Mitchell and d'Entremont, 2012), and at $-40.5^{\circ} \mathrm{C}<T<0{ }^{\circ} \mathrm{C}$ in wave clouds over continental mountains (Heymsfield and Miloshevich, 1993). Mixedphase clouds are persistent in both the Arctic and in tropical regions, as they happen nearly half of the time in the western Arctic, also known as Northwestern Territories, Canada (Shupe et al., 2006). Moreover, such clouds are an important part of tropical convective storms, as airborne observations indicate large amounts of supercooled water in these storms (Rosenfeld and Woodley, 2000). They also constitute a large portion of the cloud fraction in mid-latitude storms track (e.g., Hobbs, 1978; Matejka et al., 1980). However, a lack of observations in mixed-phase clouds (resulting from the challenge of detecting layers of supercooled liquid water in the ice-dominated parts of clouds) impeded an accurate computation of the liquid water content (LWC)-to-IWC ratio, which therefore limits an understanding of phase partitioning (Kalesse et al., 2016). Wind tunnel experiments by Takahashi and Fukuta (1988) and Fukuta and Takahashi (1999) measured the riming enhancement as an increase in ice particle fall speed $(V)$. They also showed that riming has a peak at $-10.5^{\circ} \mathrm{C}$ for low LWCs, where ice particles are isometric, and therefore have higher $V$. In addition, the reason is partly due to different collision efficiencies for planar versus isometric ice particles.

The wind tunnel experiment of Pflaum and Pruppacher (1979) showed that a cone-like graupel forms, when riming occurs on the bottom side of a falling planar crystal. However, if the particle flips over during fallout, a lump graupel forms ultimately. Heymsfield (1982) developed a parcel model, and demonstrated that growth of ice crystals by riming occurs on their minor axis, and therefore they evolve to graupel with a spherical shape of the same dimension. In this model, accreted mass fills in the unoccupied volume of the ultimately spherical graupel via riming growth. Therefore, ice particle mass increases while ice particle maximum dimension is conserved. The increase in dimension due to riming initiates once the ice particle obtains a spherical shape. This method was employed by several models to represent riming (Morrison and Grabowski, 2008; hereafter MG08; Morrison and Grabowski, 2010; Jensen and Harrington, 2015; hereafter JH15; Morrison and Milbrandt, 2015).

Note that riming occurs only when ice particles have a $D$ greater than the riming threshold size ( $D_{\text {thres }}$ : the small- est ice crystal $D$ for which riming can occur). Early observations (Harimaya, 1975) and numerical studies (Pitter and Pruppacher, 1974; Pitter, 1977) determined a $D_{\text {thres }}$ being around $300 \mu \mathrm{m}$. However, it was later shown by both observational (Bruntjes et al., 1987) and numerical (WJ00) studies that such $D_{\text {thres }}$ is around 35,110 , and $200 \mu \mathrm{m}$ for hexagonal columns, hexagonal plates, and broad-branched crystals, respectively (note that all these dimensions are along the $a$ axis of crystals, the $a$-axis being the axis along the basal face of a hexagonal ice crystal, as shown in Fig. B1 of Erfani and Mitchell, 2016).

Many models calculated ice particle mass by assuming that ice particles are spherical (e.g., $m=\rho_{i} \pi D^{3} / 6$, where $\rho_{i}$ is ice density; Rutledge and Hobbs, 1984; Ferrier, 1994; Morrison and Gettelman, 2008). However, this assumption is not realistic, and produces errors in the evolution of snowsize spectra (Mitchell, 1988). Based on observations, several studies developed ice particle mass - dimension $(m-D)$ power law parameterizations to reduce the dimensionality of complex ice particle shapes. For a specific ice particle shape or an environmental condition, this relationship has the following form:

$m=\alpha D^{\beta}$,

where both $\alpha$ and $\beta$ are constants over a specific size range. They are determined via direct measurements of ice particle mass and dimension (Locatelli and Hobbs, 1974; M90), or are constrained through aircraft measurements of the ice particle size distribution (PSD) and IWC (Heymsfield et al., 2010; Cotton et al., 2013). The prefactor $\alpha$ was considered to contain information on particle density and thickness, whereas $\beta$ was believed to have information on particle shape. We will discuss the latter in Sect. 4.1 for the riming process. Similar power laws have been developed for projected area - dimension $(A-D)$ relationships:

$A=\gamma D^{\delta}$,

where $\gamma$ and $\delta$ are constants over a specific size range derived by direct measurements of ice particle projected area and dimension (M96). When comparing rimed particles with the same size, lump graupel has the largest mass and area relative to cone-like graupel or hexagonal graupel, and densely rimed dendrites have still lower values (Locatelli and Hobbs, 1974; M96). For a specific ice habit, the $m-D$ and $A-D$ power laws are dependent on the size range considered, and it often takes two or even three $m-D$ power laws to describe a given $m-D$ relationship over all relevant sizes for that habit. To address this issue, Erfani and Mitchell (2016; hereafter EM16) developed a single $m-D$ and $A-D$ second-order polynomial curve fit in $\log -\log$ space for $20 \mu \mathrm{m} \leq D \leq 4000 \mu \mathrm{m}$ for each cloud type (synoptic or anvil) and temperature range. Such expressions can easily be reduced to power laws for use 
in models and remote sensing, and provide size-dependent power law coefficients $(\alpha, \beta, \gamma$, and $\delta)$. For this reason, they are useful for characterizing a gradual change in power law coefficients with ice particle growth. For more details on $m-D$ and $A-D$ expressions, see EM16.

\subsection{Treatment of riming in models}

Since explicit modeling of the riming process is computationally expensive, graupel and hail categories were not considered in some bulk microphysics parameterizations used in some global climate models or GCMs (Morrison and Gettelman, 2008; Gettelman and Morrison, 2015). The common ice microphysics approach in most cloud and climate models is the separation of ice into various hydrometeor categories such as cloud ice, snowflakes, and graupel (Rutledge and Hobbs, 1984; Ferrier, 1994; Fowler et al., 1996; Reisin et al. 1996; Morrison and Gettelman, 2008; Gettelman and Morrison, 2015). The transition between various hydrometeors occurs by autoconversion from one hydrometeor category to another. However, such autoconversion is arbitrary and poorly constrained, and as shown by Eidhammer et al. (2014), cloud radiative properties were sensitive to the choice of autoconversion threshold size in the Community Atmosphere Model version 5 (CAM5). This is because the distinct boundaries between various ice hydrometeor categories impose abrupt changes in microphysical properties (such as ice particle mass, projected area, fall speed, and effective diameter) from one hydrometeor category to another, while in nature the transition processes are gradual.

To overcome this problem, MG08 advanced a bulk model that employed vapor diffusion and the riming processes, and used multiple $m-D$ and $A-D$ power laws (Eqs. 1 and 2) to characterize ice particles associated with different parts of the PSD. This method was applied to a bin model developed by Morrison and Grabowski (2010), and was later used in a bulk model that prognoses number concentration, rime volume, rime mass, and total mass (Morrison and Milbrandt, 2015). In this approach, different $m-D$ and $A-D$ expressions from the literature are used for either pure ice crystals or graupel. Then, $m$ and $A$ are calculated in a transitional step as a function of $D$ and rimed mass fraction. Such $m-D$ and $A-D$ expressions resulted in a gradual transition from crystal mass to graupel mass. However, discontinuities were observed in the transition between various $A-D$ expressions over the PSD because the size range for each microphysical step (ice crystal, graupel, and transition) was calculated in a way to provide only continuous mass, and thus produced discontinuities in projected area. JH15 developed a detailed ice growth model that simulates ice particle habit and mass via the processes of vapor deposition and riming. This model is also a single-category scheme, but it does not employ $m-D$ and $A-D$ power laws; instead, it computes the growth of ice particles along the major and minor axes of oblate or prolate spheroids (representing hexagonal plates or columns). There- fore, the model is able to simulate simple ice particle shapes, and also captures the temperature dependency of vapor deposition and the riming processes (since particle shape is a function of temperature and relative humidity; Magono and Lee, 1966; Pruppacher and Klett, 1997). The simulated ice particle shape, mass, and fall speed are in good agreement with observational data from wind tunnel experiments on ice crystal growth.

The computation of rime mass (an increase in ice particle mass by riming) in models is performed by calculating the accretional mass growth rate (Heymsfield, 1982; Mitchell, 1995; JH15). When an ice particle falls in a cloud of supercooled cloud droplets, the increase in its mass due to accretion depends on ice particle features (e.g., fall speed and projected area), droplet characteristics (e.g., mass and number concentration of droplets), and the collision efficiency $\left(E_{\mathrm{c}}\right)$ between an ice particle and droplet. More details on mass growth rates are provided in Sect. 6, and $E_{\mathrm{c}}$ is described in the next section.

\subsection{Collision efficiency}

One important factor in the modeling of riming is the calculation of the $E_{\mathrm{c}}$ between ice particles and cloud droplets (Pruppacher and Klett, 1997). $E_{\mathrm{c}}$ was calculated as a function of ice particle $D$ and cloud droplet diameter $(d)$ via both experimental measurements (Sasyo and Tokuue, 1973, hereafter ST73; Kajikawa, 1974, hereafter K74; Murakami et al., 1985) and theoretical-numerical calculations (Beard and Grover, 1974; Pitter and Pruppacher, 1974; Schlamp et al., 1975; Pitter, 1977; Wang and Ji, 2000, hereafter WJ00). The difference in $E_{\mathrm{c}}$ between various studies is due to the strong sensitivity of $E_{\mathrm{c}}$ to the ice particle shape as well as the assumptions and limitations in different studies. Experimental measurements of $E_{\mathrm{c}}$ have been conducted in vertical wind tunnels. Such studies are rare due to the difficulty and limitations of experiments, and were limited to only planar ice crystals or circular disks with $D>1 \mathrm{~mm}$ (Reynolds number $(R e)>40)$. Murakami et al. (1985) studied the $E_{\mathrm{c}}$ between polystyrene latex spheres $(d<6 \mu \mathrm{m})$ and freely falling planar ice crystals $(1.5 \mathrm{~mm}<D<5 \mathrm{~mm}$, and $70<R e<300)$. ST73 investigated fixed hexagonal plates $(5 \mathrm{~mm}<D<20 \mathrm{~mm})$ that were exposed to water droplets contained in airflow in a vertical wind tunnel. Although $d$ ranged from 19 to $41 \mu \mathrm{m}$, more than $80 \%$ of droplets had $d$ between 20 and $25 \mu \mathrm{m}$. K74 measured $E_{\mathrm{c}}$ via collection of water droplets $(2.5 \mu \mathrm{m}$ $<d<17.5 \mu \mathrm{m}$ ) by freely falling particles (both natural snow crystals and ice crystal models made of non-water substance) of various shapes (e.g., circular disks, hexagonal plates, and broad-branched plates) with $R e<100$ in a wind tunnel.

Numerical studies calculate the flow field around particles by solving the Navier-Stokes equation via numerical methods. The challenges for numerical studies are the complex shapes of ice crystals as well as the effect of turbulence. Early studies assumed steady-state flow with simplified shapes 
such as an oblate spheroid with $2 \leq R e \leq 20$ as an approximation for planar crystals (Pitter and Pruppacher, 1974; Pitter, 1977), and an infinite cylinder with $0.2 \leq R e \leq 20$ as an approximation for columnar crystals (Schlamp, 1975). The main difference in $E_{\mathrm{c}}$ between experimental and numerical studies is observed for small droplets $(d<10 \mu \mathrm{m})$, where numerical $E_{\mathrm{c}}$ is zero in this range, but the experimental results indicate finite $E_{\mathrm{c}}$. As explained by $\mathrm{K} 74$, this difference might be due to the assumption of a steady flow field around the ice particle in the early numerical studies. WJ00 developed a numerical model of 3-D non-steady flow around pristine crystals (such as hexagonal plates with $1 \leq R e \leq 120$ and columnar crystals of finite length and with $0.2 \leq R e \leq 20$ ) and water droplets $(d<200 \mu \mathrm{m})$. Contrary to early numerical studies and in agreement with experimental results, they showed that $E_{\mathrm{c}}$ for small droplets has finite values for hexagonal plates (hexagonal columns) with $R e \geq 10(R e \geq 0.2)$.

Due to its expensive computation, $E_{\mathrm{c}}$ is sometimes assumed to be constant in the models (e.g., $E_{\mathrm{c}}=0.75$ in MG08; $E_{\mathrm{c}}=1$ in Rutledge and Hobbs, 1984; Ferrier, 1994; Fowler et al., 1996; Morrison and Milbrandt, 2015). Hall (1980; hereafter H80) provided an equation for $E_{\mathrm{c}}$ representative of hexagonal plates by fitting ellipse curves to the data of Pitter and Pruppacher (1974) and Pitter (1977). Although this relationship is practical and was used by several models (Morrison and Grabowski, 2010; JH15; Kalesse et al, 2016), it has limitations due to the natural shortcomings of the original numerical studies (assumptions of steady flow, ice oblate spheroids with $R e<20$ as an approximation for hexagonal plates, water droplets with $d<20 \mu \mathrm{m}$, and zero $E_{\mathrm{c}}$ for $\left.d<10 \mu \mathrm{m}\right)$. WJ00 improved the computation of $E_{\mathrm{c}}$ by solving these issues, but did not provide an equation for use in the models. JH15 modified the equation from Beard and Grover (1974) for spherical raindrops in steady flow, and calculated $E_{\mathrm{c}}$ between prolate spheroids (as an approximation for hexagonal columns) and small water droplets. $E_{\mathrm{c}}$ calculated in this way compares well with the numerical study of WJ00 for $5 \mu \mathrm{m}<d<20 \mu \mathrm{m}$.

Another challenge exists in the calculation of $E_{\mathrm{c}}$ between graupel and cloud droplets. Most studies used $E_{\mathrm{c}}$ from Beard and Grover (1974), and therefore assumed that this $E_{\mathrm{c}}$ is equal to the collision efficiency between raindrops and water drops (Reisin et al., 1996; Pinski et al., 1998; Khain et al., 1999; Morrison and Grabowski, 2010). The justification for this assumption was the similar shape between graupel and raindrops. However, such particles have different natural features (e.g., density and surface roughness). To solve this issue, Rasmussen and Heymsfield (1985) suggested that $E_{\mathrm{c}}$ between graupel and cloud droplets can be calculated by modification of the results of Beard and Grover (1974) for $E_{\mathrm{c}}$ between raindrops and water droplets. Similar to Beard and Grover (1974), they employed the superposition method for collision between particles, but they assumed that the small cloud droplets do not change the graupel fall speed, and therefore they used Stokes number instead of mixed Froude number in the non-dimensionalized momentum equation (see Eqs. 1-6 in Rasmussen and Heymsfield, 1985). On the other hand, von Blohn et al. (2009) investigated experimental $E_{\mathrm{c}}$ between freely falling spherical ice particles (initially $580 \mu \mathrm{m}<D<760 \mu \mathrm{m}$ ) and water droplets $(20 \mu \mathrm{m}<d<40 \mu \mathrm{m})$ in a vertical wind tunnel with laminar flow. They showed that collection kernels of ice particles are higher than that of raindrops, and therefore calculated a correction factor to account for the error in $E_{\mathrm{c}}$, when assuming raindrops instead of graupel.

The objective of this study is to develop various empirical and theoretical approaches to represent the continuous and gradual growth of ice particle mass and projected area during riming in a realistic and yet simple way, suitable for models. Section 2 of this study explains the data and method. In Sect. 3, results from a ground-based field campaign are applied to investigate $m-D$ relationships during riming. Section 4 introduces a method to parameterize riming. In Sect. 5, new practical equations are presented to calculate $E_{\mathrm{c}}$ for hexagonal plates and hexagonal columns. Calculations of the mass growth rate due to riming are given in Sect. 6, and conclusions are provided in Sect. 7.

\section{Data and methods}

Ground-based direct measurements of $m$ and $D$ from the Sierra Cooperative Pilot Project (SCPP; see M90) during winter storms in the Sierra Nevada are utilized in this study. SCPP was a field campaign on cloud seeding from 1986 to 1988 , and for one part of that project, natural ice particles were collected during snow storms in a polystyrene petri dish and then the particles were photographed using a microscope equipped with a camera. Then a heat lamp was used to melt these ice particles, and immediately after melting another photograph was taken of the hemispheric water drops (contact angle on polystyrene $=87.4^{\circ}$ ). The images were used later in the lab to measure the maximum dimension $(D)$ of individual ice particles (defined as diameter of a circumscribed circle around the particle). In addition, the diameter of the water hemispheres was measured, and from this the volume and mass of individual ice particles were computed. Also recorded were individual ice particle shapes, which were classified using the Magono and Lee (1966) nomenclature scheme. The level of riming (i.e., light, moderate, heavy riming, or graupel) was indicated based on this scheme, and the temperature range over which the observed ice particle shape originated was recorded (e.g., for long columns, $-8^{\circ} \mathrm{C}<T<-6^{\circ} \mathrm{C}$ ). These riming levels are indicated (with rimed crystal illustrations) in the Magono and Lee (1966) ice particle classification scheme with the prefixes R1, R2, R3, and R4 (see Pruppacher and Klett, 1997). Photographic examples of these rimed particle types are shown in Fig. 2 of Locatelli and Hobbs (1974). Software was developed to extract all combinations of particle shapes (for a detailed expla- 
Table 1. Description of the bin intervals of PSD.

\begin{tabular}{lrrr}
\hline $\begin{array}{l}\text { Bin } \\
\text { number }\end{array}$ & $\begin{array}{r}\text { Bin lower } \\
\text { point }(\mu \mathrm{m})\end{array}$ & $\begin{array}{r}\text { Bin upper } \\
\text { point }(\mu \mathrm{m})\end{array}$ & $\begin{array}{r}\text { Bin width } \\
(\mu \mathrm{m})\end{array}$ \\
\hline 1 & 100 & 200 & 100 \\
2 & 200 & 300 & 100 \\
3 & 300 & 400 & 100 \\
4 & 400 & 500 & 100 \\
5 & 500 & 600 & 100 \\
6 & 600 & 700 & 100 \\
7 & 700 & 800 & 100 \\
8 & 800 & 900 & 100 \\
9 & 900 & 1000 & 100 \\
10 & 1000 & 1200 & 200 \\
11 & 1200 & 1400 & 200 \\
12 & 1400 & 1800 & 400 \\
13 & 1800 & 2400 & 600 \\
14 & 2400 & 3000 & 600 \\
15 & 3000 & 4000 & 1000 \\
\hline
\end{tabular}

nation of sampling and measurements, see M90). SCPP is a unique dataset that measures both ice particle size and mass and also determines the degree of riming. As explained in EM16, the important problem with airborne measurements is that they are unable to measure single ice particle mass. Nonetheless, we compare our results with $m-D$ relationships from previous studies (Heymsfield et al., 2010; Cotton et al., 2013; EM16) that are based on airborne measurements.

EM16 provided $m-D$ curve fits based on cloud particle imager (CPI) measurements from the Department of Energy (DOE)-Atmospheric Radiation Measurement (ARM)funded Small Particles In Cirrus (SPartICus) field campaign for $D<100 \mu \mathrm{m}$ and a subset of SCPP data for $D>100 \mu \mathrm{m}$. Since CPI does not measure ice particle mass, EM16 developed a method that calculates mass from the measurements of the ice particle projected area, $D$, and aspect ratio by assuming that small ice particles can be approximated as hexagonal columns (for more details, see Appendix B in EM16). The subset of SCPP used in EM16 includes only unrimed ice particles that have habits identical to those in cirrus clouds (selected based only on ice particles that have habits formed in the temperature range between -40 and $-20^{\circ} \mathrm{C}$ ). There are 827 ice particles that are categorized in this subset. Hereafter, this subset of SCPP data is referred to as "coldhabit SCPP". The SCPP data have a total of 4869 ice particles, consisting of 2341 unrimed or lightly rimed particles (such as plates, dendrites, columns, needles, bullets, bullet rosettes, side planes, and aggregates and fragments of these shapes), 1440 moderately or heavily rimed particles (such as rimed plates, rimed dendrites, rimed columns, and graupel), and 1088 unclassified particles. There were 118 unrimed dendrites, including ordinary, stellar, and fern-like dendrites, classified using the Magono and Lee (1966) scheme as P1e, $\mathrm{P} 1 \mathrm{~d}$, and P1f, respectively, as well as fragments and aggre- gates of these shapes. $80 \%$ of unrimed dendrites were P1e. Columnar crystals consisted of $262 \mathrm{~N} 1 \mathrm{e}$ (long solid columns) and $337 \mathrm{C} 2 \mathrm{~b}$ (combination of long solid columns) crystals. Some ice crystals classified as unrimed may be lightly rimed due to limitations in the magnification used. Moreover, 852 particles were classified as heavily rimed dendrites, consisting of graupel-like snow of hexagonal type (R3a), graupellike snow of lump type (R3b), and graupel-like snow with nonrimed extensions (R3c), of which $99 \%$ were R3b. These correspond to heavily rimed dendrites having graupel-like centers but with rimed branches extending outwards revealing the dendritic origin. Also classified were a total of 67 lump graupel (R4b), cone-like graupel (R4c), and hexagonal graupel (R4a); R4b and R4c are graupel with non- discernable original habit, whereas $\mathrm{R} 4 \mathrm{a}$ forms just prior to $\mathrm{R} 4 \mathrm{~b}$ or $\mathrm{R} 4 \mathrm{c}$, with its hexagonal origin still recognizable.

In order to represent the natural variability of ice particle mass, all identifiable particles are initially shown with their actual mass and maximum dimension. Thereafter, to quantify the variability and to further investigate $m-D$ power laws and the rimed-to-unrimed mass ratio, the ice PSDs were divided into size bins with intervals of $100 \mu \mathrm{m}$ between 100 and $1000 \mu \mathrm{m}$, and with subsequent intervals of 200, 200, 400, 600,600 , and $1000 \mu \mathrm{m}$ (up to $4000 \mu \mathrm{m}$ ) at larger sizes to supply sufficient sampling numbers in each size bin (for more details on bin intervals, see Table 1). In order to investigate the riming effect, all identifiable particles were sorted into either one of three rimed categories or an unrimed category. Both unrimed and lightly rimed ice particles are included in the unrimed category, whereas the three rimed categories consist of densely rimed, heavily rimed, and graupel particles.

\section{Measurements of ice particle mass and dimension in frontal clouds}

The purpose of this section is to demonstrate how the coldhabit SCPP curve fit from EM16 (based on unrimed ice crystals) compares with all the SCPP data, since this shows how the EM16 curve fit appears representative for all ice particles sampled during SCPP and thus may be representative for Sierra Nevada snowfall. This comparison is shown in Fig. 1a for all ice particles that could be classified (3781 ice particles). The curve fit appears to bisect the data well. Moreover, it is seen that rimed ice particles tend to have larger mass on average, compared to unrimed ice particles of the same size. We discuss this with more details in Sect. 4.1. Also displayed are the $m-D$ power law expressions from Cotton et al. (2013) and Heymsfield et al. (2010) which were acquired from synoptic ice clouds for $-60^{\circ} \mathrm{C}<T<-20^{\circ} \mathrm{C}$ and from both synoptic and anvil ice clouds for $-60^{\circ} \mathrm{C}<T<0^{\circ} \mathrm{C}$, respectively. The grey line, corresponding to spherical particles having density equal to $0.917 \mathrm{~g} \mathrm{~m}^{-3}$ (solid ice density), serves as an upper limit to ice particle mass. The Cotton et 
(a)

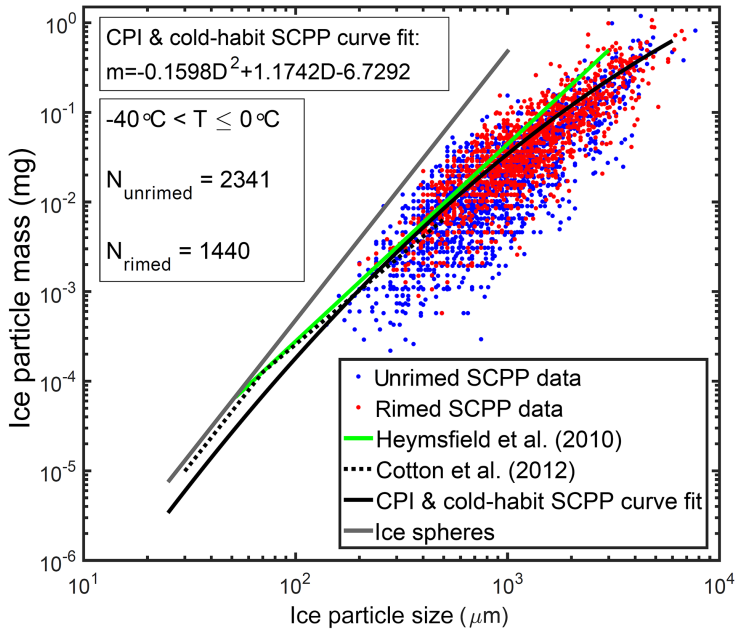

(b)

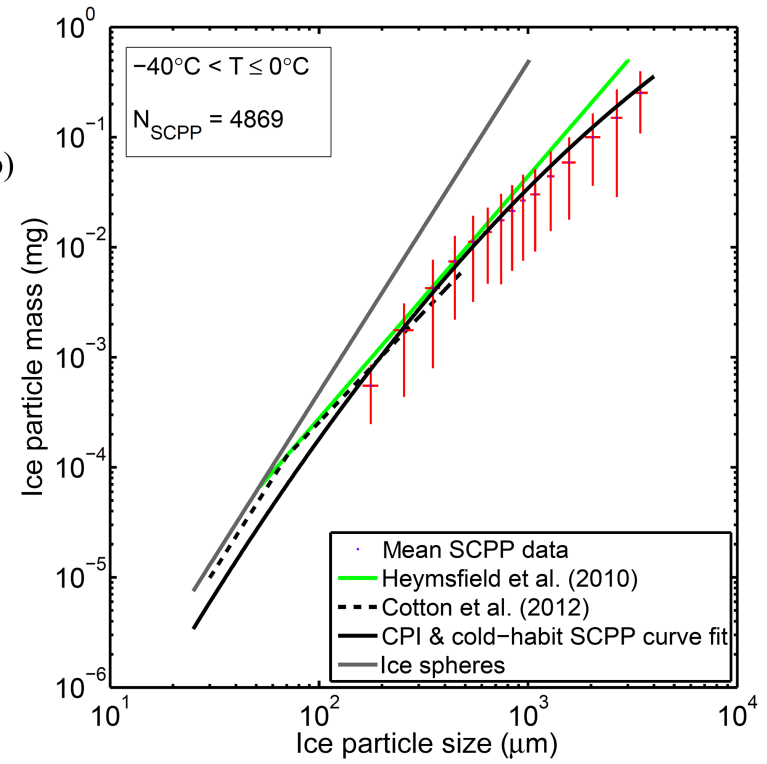

Figure 1. (a) Comparing the $m-D$ curve fit based on the CPI and cold-habit SCPP data (EM16) with SCPP ice particle $m-D$ measurements corresponding to all classifiable shapes. Unrimed and rimed particles are indicated by blue and red dots, respectively. The $m-D$ power laws from two other studies are also displayed. (b) Similar to (a), except that all the SCPP data (including unclassifiable ice particles) have been grouped into size bins; mean (red cross-intersection points) and standard deviation (red bars) in each size bin are shown.

al. (2013) expression is composed of two power laws that differ from the EM16 curve fit by less than $50 \%$ (over its size domain). The Heymsfield et al. (2010) expression is based on a single power law and it also estimates the curve fit well, except for the size ranges $D>1000$ and $D<100 \mu \mathrm{m}$, where the differences in mass can reach about $100 \%$.

Figure $1 \mathrm{~b}$ displays the EM16 curve fit along with all SCPP data (including those that could not be classified), where the ice PSDs were divided into size bins, as explained in Sect. 2. In this way, mean $D$ and $m$ in each size bin, and also the

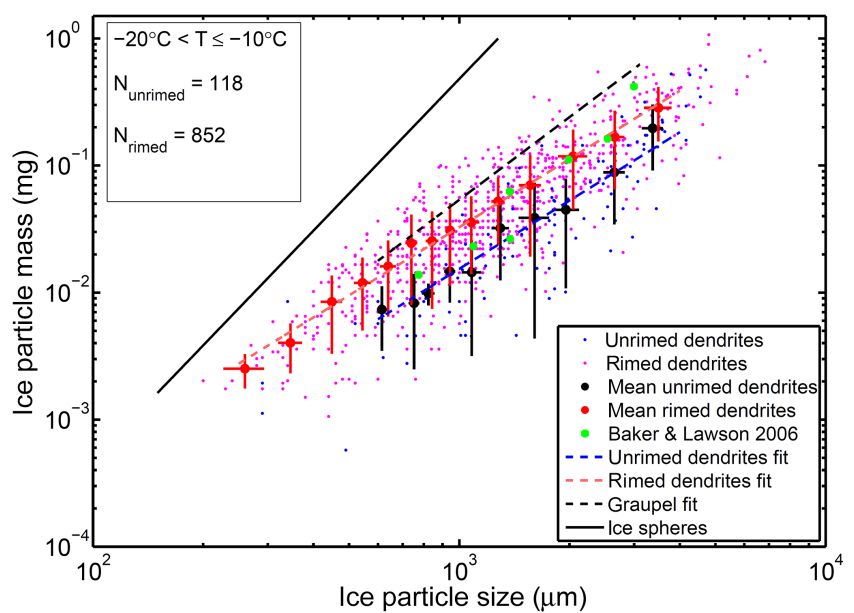

Figure 2. Ice particle $m-D$ measurements corresponding to rimed (pink dots) and unrimed (blue dots) dendrites using SCPP data. Mean (circles) and standard deviations (bars) in each size bin are also displayed for both rimed (red) and unrimed (black) dendrites. Green filled circles indicate dendrites from BL06.

standard deviation $(\sigma)$ in each size interval for $D$ and $m$, are shown. Figure 1b shows that the EM16 curve fit is well within the $\sigma$ of SCPP mass and is close to the mean $m$ for all size bins. The same is valid for the Cotton et al. (2013) $m-D$ line over its size domain. The Heymsfield et al. (2010) line is within the $\sigma$ of SCPP for $250 \mu \mathrm{m}<D<1400 \mu \mathrm{m}$. In order to be even more quantitative, the percent difference between the total SCPP mean ice particle mass in each size bin of Fig. $1 \mathrm{~b}$ and the corresponding mass from the cold-habit SCPP curve fit from EM16 are computed (figure not shown). For $D>200 \mu \mathrm{m}$, percent differences are no more than $22 \%$, with the curve fit slightly overestimating masses for $D$ greater than $1000 \mu \mathrm{m}$. This agreement might result partially from the riming of the planar ice crystals and aggregates thereof (adding mass with little change in size) and partially from an abundance of unrimed and rimed high-density compact ice particles. Indeed, $38 \%$ of the ice particles were moderately-to-heavily rimed. To summarize, it appears that the EM16 synoptic ice cloud curve fit for $-40^{\circ} \mathrm{C}<T \leq-20^{\circ} \mathrm{C}$ provides a realistic bulk estimate for ice particle masses in Sierra Nevada winter snowstorms at ground level.

\section{Parameterization of riming}

\subsection{Dependence of $\beta$ and $\alpha$ on riming}

A long-standing problem in cloud modeling is the treatment of $\alpha, \beta, \gamma$, and $\delta$ as a function of ice particle riming. Since riming leads to graupel formation and graupel tends to be quasi-spherical, it is intuitive to assume that $\beta$ and $\delta$ will approach limiting values of 3 and 2 , respectively (corre- 
sponding to ice spheres), as more and more supercooled liquid water is accreted by an ice particle to produce graupel. One common approach in many cloud models (that use an $m-D$ relationship) is to assume that $\beta$ is equal to $\sim 2$ for unrimed crystals and is equal to $\sim 3$ for graupel. This implies that riming enhances $\beta$. This assumption is tested in this section by using SCPP data with the objective of developing observation-based guidelines for modeling the process of riming. To test this assumption for $\beta$, the size-resolved masses of rimed and unrimed ice particles from the same basic shape category are needed. In this section, we used heavily rimed dendrites (R3a, R3b, and R3c) and unrimed dendrites (P1e, P1d, and P1f). In addition, these data were partitioned into the same size intervals described earlier to calculate the mean $m$ and $D$ in each size interval for unrimed and heavily rimed dendrite crystals, along with their $\sigma$. All these results are shown in Fig. 2. Size intervals having less than three measurements are not represented. Most of the data for unrimed crystals is associated with $D>600 \mu \mathrm{m}$. One can see quantitatively how the mean masses for rimed dendrites are substantially greater than those for unrimed dendrites on average for the same size interval, in agreement with the hypothesis of Heymsfield (1982).

Using only the size intervals containing at least three measurements, the $m-D$ power law for the unrimed dendrites is as follows:

$m=0.001263 D^{1.912}$.

For heavily rimed dendrites it is as follows:

$m=0.001988 D^{1.784}$,

where all variables have cgs (centimeter-gram-second) units. If the size interval corresponding to the largest unrimed dendrites is not used in the least-square fit calculation, the $m-D$ expression for unrimed dendrites becomes the following:

$m=0.0009393 D^{1.786}$,

having an exponent nearly identical to that in Eq. (4) for heavily rimed dendrites. This is contrary to most cloud models that assume different ice categories (snowfall with $\beta \sim 2$ and graupel with $\beta \sim 3$ ) and an abrupt increase in $\beta$ upon a change in ice category (autoconversion). Based on SCPP observations, it is apparent that the traditional hypothesis that $\beta$ increases with riming is not correct, at least not before the graupel onset. This can be understood by noting that $\beta$ does not necessarily indicate the morphology of an ice particle within a given size interval, but rather indicates the mass rate-of-change with respect to size (since $\beta$ is the slope of the $m-D$ line in $\log -\log$ space). This can also be seen qualitatively in Fig. 2, where the rimed and unrimed data points represent the same slope for the $m-D$ line in $\log -\log$ space. Assuming that unrimed dendrite mass conforms to the formula $m=\rho_{i} \pi D^{3} / 6$, where $\rho_{i}$ is a reduced density, such $\rho_{i}$ is equal to $0.07 \mathrm{~g} \mathrm{~cm}^{-3}$ for $D=500 \mu \mathrm{m}$. Note that this assumption would lead to a fit parallel to the ice spheres fit in Fig. 2, with a relatively low coefficient of determination $\left(R^{2}=0.68\right)$, compared to power law fit with $R^{2}=0.97$. In addition, the $m-D$ power law for lump graupel (R4b) and cone-like graupel (R4c) has the form of $m=0.0078 D^{2.162}$, which represents a slight increase in $\beta$ for graupel which is significantly less than spherical $\beta$ (which is equal to 3). By assuming that initial graupel mass can be calculated as $m=\rho_{i} \pi D^{3} / 6$ where $\rho_{i}$ is a reduced density, such $\rho_{i}$ is equal to $0.18 \mathrm{~g} \mathrm{~cm}^{-3}$ for $D=500 \mu \mathrm{m}$, which is lower than the $\rho_{i}$ for heavily rimed graupel in the dry growth regime ( $\rho_{i}=0.4 \mathrm{~g} \mathrm{~cm}^{-3}$; Rutledge and Hobbs, 1984; Ferrier, 1994). This assumption would produce a fit parallel to the ice spheres fit in Fig. 2, and is poorly fitted to the SCPP $\mathrm{R} 4 \mathrm{~b}$ and $\mathrm{R} 4 \mathrm{c}$ data $\left(R^{2}=0.67\right)$, compared to the power law fit $\left(R^{2}=0.94\right)$.

All these observations are in agreement with the experiment of Rogers (1974) in which $\beta$ was similar for unrimed and rimed snowflakes. The results of Rogers (1974) were used in the modeling work of MG08 and Morrison and Grabowski (2010) to support the assumption that riming does not change $\beta$ for planar ice crystals. Morrison and Milbrandt (2015) used a similar assumption based on the observations of Rogers (1974) and Mitchell and Erfani (2014), and they explained that the reason for the conservation of $\beta$ during riming is the fact that $D$ does not significantly change by riming while $m$ does increase significantly. This reasoning appears valid for both planar and columnar ice crystals. The impact of moderate to heavy riming on $\beta$ for hexagonal columns was demonstrated in M90 (see their Table 1 and Sect. 4d). For these columnar crystals, riming had no effect on $\beta$ (i.e., $\beta$ was 1.8 for both rimed and unrimed columns), indicating that riming can be modeled by only increasing $\alpha$ for these crystals. Thus, it appears justified to treat $\beta$ as constant during the riming process (until spherical shape) for both dendritic and columnar ice crystals:

$\beta=\beta_{\mathrm{u}}$,

where subscript $u$ denotes unrimed conditions. The IWC is defined as follows:

$\mathrm{IWC}=\int m(D) n(D) \mathrm{d} D=\alpha \int D^{\beta} n(D) \mathrm{d} D$,

where $n(D)$ is number distribution. We explained that $\beta$ and $D$ do not change during riming. Also unchanged is $n(D)$, because the number of ice particles in each size bin is not affected by riming. Therefore, the dependence of $\alpha$ on riming 


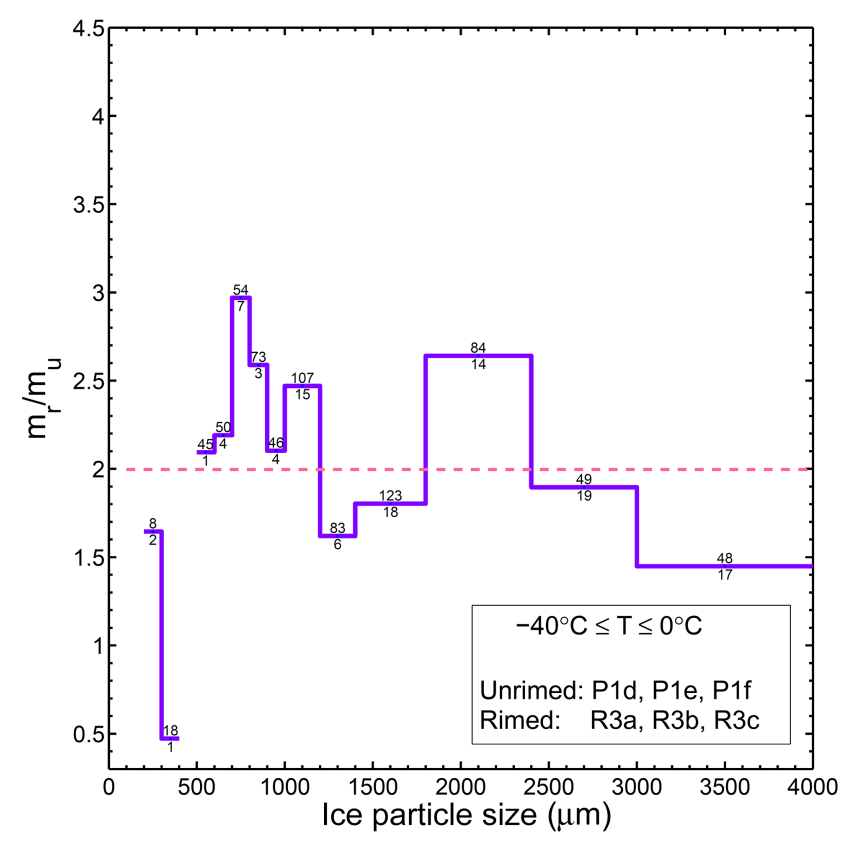

Figure 3. Rimed-to-unrimed mass ratio $m_{\mathrm{r}} / m_{\mathrm{u}}$ (violet lines) for each common size bin in Fig. 2, based on heavily rimed and unrimed dendrites. The pink line indicates the weighted mean of $m_{\mathrm{r}} / m_{\mathrm{u}}$. The numbers on the top (bottom) of each violet line show the number of rimed (unrimed) particles in that size bin.

can be calculated by knowing the contribution of riming to the IWC:

$$
\frac{\alpha}{\alpha_{\mathrm{u}}} \approx \frac{\mathrm{IWC}}{\mathrm{IWC}_{\mathrm{u}}}
$$

Since $\beta$ is essentially the same in Eqs. (4) and (5), their prefactor ratio ( $\alpha$ in Eq. 4 divided by $\alpha$ in Eq. 5, which is equal to 2.12 ) indicates that riming contributed slightly more than half the mass of the rimed dendrites. This can be confirmed by calculation of the ratio of mean rimed dendrite mass $\left(m_{\mathrm{r}}\right)$ to mean unrimed dendrite mass $\left(m_{\mathrm{u}}\right)$ for each common size interval, as shown in Fig. 3. This riming ratio $\left(m_{\mathrm{r}} / m_{\mathrm{u}}\right)$ for each size bin varies from $\sim 0.5$ to 3 with many values close to 2 . The weighted average of $m_{\mathrm{r}} / m_{\mathrm{u}}$ is equal to 2.0 , supporting the first estimate of 2.12. The largest deviation from the mean for $300 \mu \mathrm{m}<D<400 \mu \mathrm{m}$ may be due to only a single unrimed ice crystal of anomalous mass in this size bin.

Equations (4) and (5) also suggest a means of adapting the $m-D$ curve fit in Fig. 1 for modeling the riming process in mixed-phase clouds. Since this curve fit is representative of ice particle populations in frontal clouds (containing a mixture of unrimed and rimed particles), it can be adapted for modeling the riming process in frontal clouds. Since $\beta$ should be essentially the same for both unrimed and the mixture of unrimed plus rimed SCPP ice particles, the ratio of their corresponding prefactors (i.e., $\alpha_{\mathrm{u}} / \alpha_{\text {mix }}$ ) can be multiplied by the mass predicted by the curve fit equation to yield the masses appropriate for unrimed particles. For the ice particles plotted in Fig. 1a, $m_{\mathrm{u}} / m_{\mathrm{mix}}$ is equal to 0.650 (where $m_{\text {mix }}$ includes all these particles and $m_{\mathrm{u}} / m_{\text {mix }}$ was calculated by the same method that calculated $m_{\mathrm{r}} / m_{\mathrm{u}}$ in Fig. 3). This implies that multiplying the mass predicted by the curve fit in Fig. 1 by a factor of 0.65 will yield masses proper for unrimed ice particles. To model the riming process in frontal clouds, these unrimed particles can be subjected to the riming growth equations described below as well as Eq. (8).

\subsection{Dependence of $\delta$ and $\gamma$ on riming}

MG08 used different $A-D$ power laws in each riming step, but such a method led to discontinuities in projected area during the transition from one ice category to another one. It seems that the $A-D$ and $m-D$ that they used were not selfconsistent (e.g., they were from different studies based on different datasets). Here, we suggest an approach to avoid the discontinuity in the projected area. Since there are no SCPP $A-D$ measurements that correspond with the $m-D$ measurements used in Sect. 4.1, a purely empirical evaluation of the dependence of $\delta$ and $\gamma$ on riming was not possible. However, Fontaine et al. (2014) simulated numerous ice particles (pristine crystals, aggregates, and rimed particles) with various 3-D shapes and also their projected area (assuming random orientation). By this, they were able to develop a linear expression between $\beta$ and $\delta$. This linear expression implies that $\delta$ is constant during the riming process, since $\beta$ has no riming dependency (see Sect. 4.1):

$\delta=\delta_{\mathrm{u}}$.

The reason for this can be explained by noting that the riming process often affects $A$ but does not change $D$ (by filling the space between ice particle branches) significantly prior to graupel formation. This is also evident from observations, as shown in Table 1 of M96, where $\delta$ is equal to 2 for both hexagonal plates and lump graupel. For constant $\delta$, only $\gamma$ depends on riming, and to express $\gamma$ as a function of riming, we developed a method that estimates the change in $A$ by riming as a function of the change in $m$ :

$A=\left(A_{\max }-A_{\mathrm{u}}\right) R+A_{\mathrm{u}}$,

where $A_{\max }$ is the maximum projected area due to riming in the phase 1 (which is the graupel $A$ ), and $R$ is the riming factor defined as follows:

$R=\frac{m-m_{\mathrm{u}}}{m_{\max }-m_{\mathrm{u}}}$,

where $m_{\max }$ is the graupel $m$ (having the same $D$ as $m$ and $\left.m_{\mathrm{u}}\right) . R$ is between 0 and 1 , with 0 denoting no riming and 1 indicating graupel formation. In other words, when an ice 

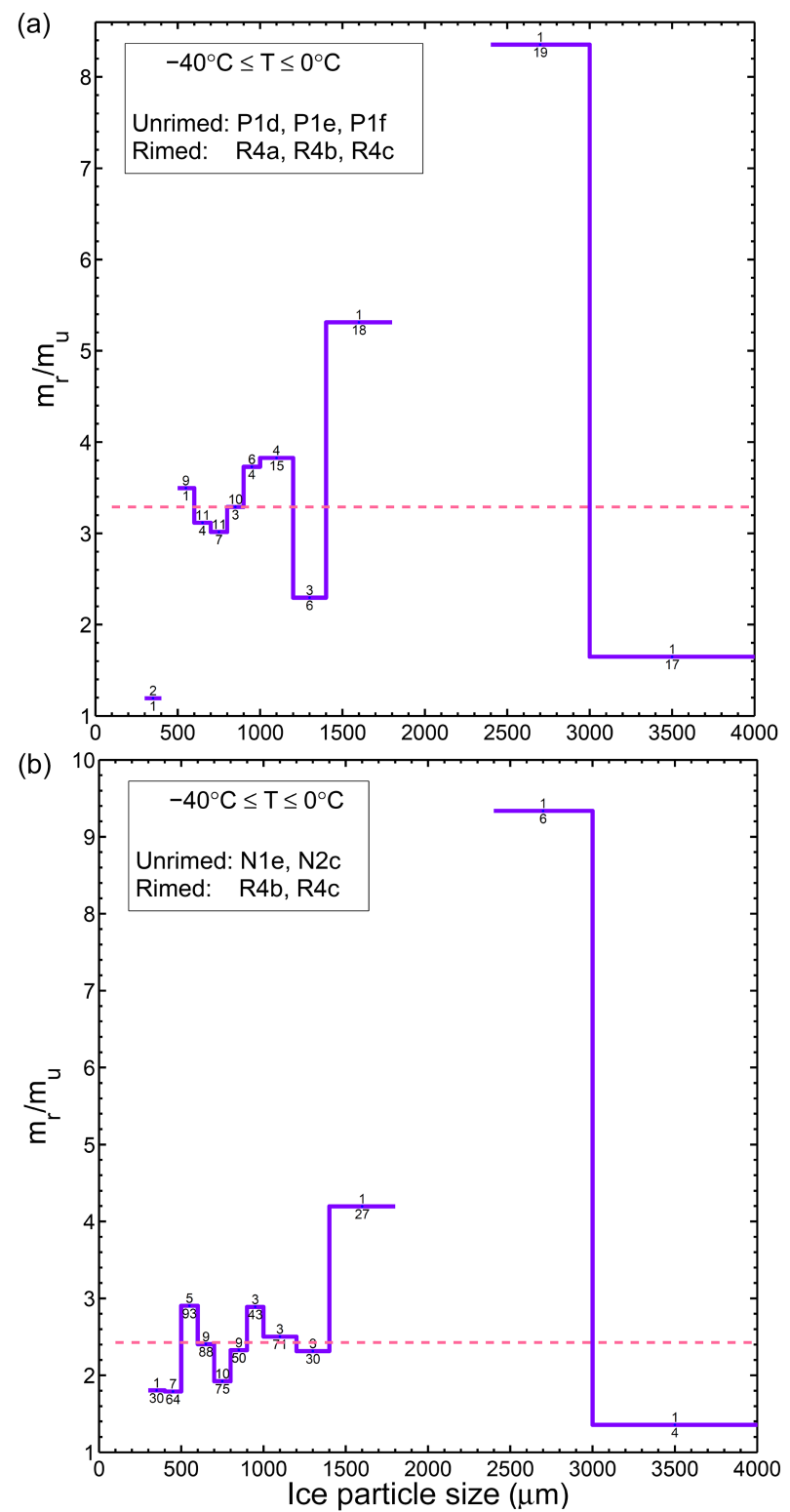

Figure 4. (a) Same as Fig. 3, but rimed particles are now graupel. (b) Same as (a), but unrimed particles are now columnar crystals and R4a (hexagonal graupel) is not included.

crystal is unrimed, $m=m_{\mathrm{u}}$ and $A=A_{\mathrm{u}}$; when $m=m_{\max }$ and $A=A_{\max }$, the ice crystal attains graupel status at the end of phase 1 . For a given $D, \gamma=A / D^{\delta}$, and in this way the riming dependence of $\alpha$ and $\gamma$ can be treated, while $\beta$ and $\delta$ are independent of riming. Note that Eq. (10) assumes a linear relationship between $m$ and $A$ during riming. This assumption can be justified, because $m \propto \frac{\alpha}{\gamma} A$ (note that $\beta, \delta$, and $D$ do not change during the phase 1 of riming); this can be investigated through future research.

\subsubsection{Planar ice crystals}

Using the approach above, $m$ (in particular, $\alpha$ ) should first be determined as a function of riming using conventional theory (this will be discussed in Sect. 6), and then Eqs. (8), (10), and (11) can be applied to calculate $A$. In order to determine $m_{\max }$, we calculated the $m_{\mathrm{r}} / m_{\mathrm{u}}$ that corresponds to graupel (R4a, R4b, and R4c) and unrimed dendrites (P1d, P1e, and P1f), as shown in Fig. 4a. Small variability is seen for $D<1200 \mu \mathrm{m}$ (ranges from 3 to 3.8, with the exception of smallest size bin), whereas large variability exists (between 1.6 and 8.4) for larger sizes due to the small number of graupel in each size bin. The weighted average for this $m_{\mathrm{r}} / m_{\mathrm{u}}$ ratio is equal to 3.3 , which can be used to estimate $m_{\max }: m_{\max } \approx 3.3 \times m_{\mathrm{u}}$ for the dendrites. Since R4a occurs just before hexagonal features are completely obscured by additional rime deposits, $\mathrm{R} 4 \mathrm{a}$ graupel is ideal for estimating $m_{\max }$. Unfortunately, there are only $14 \mathrm{R} 4 \mathrm{a}$ particles in the entire SCPP data, with $D<1200 \mu \mathrm{m}$. They exhibit a large variability in the $m_{\mathrm{r}} / m_{\mathrm{u}}$ ratio (ranging from 1.6 to 4.5 ) with a weighted average of $m_{\mathrm{r}} / m_{\mathrm{u}}$ equal to 3.1 (figure not shown). Nonetheless the close agreement with the above $m_{\mathrm{r}} / m_{\mathrm{u}}$ ratio of 3.3 is encouraging for us to conclude that initial graupel mass (at the end of phase 1) is 3.3 times larger than unrimed dendrites. Since the SCPP observations show that $D$ and $\beta$ are conserved during the phase 1 of riming, graupel density is also $\sim 3.3$ times larger than unrimed dendrite mass. A similar observational analysis was conducted by Rogers (1974), who found that $\alpha$ for heavily rimed snowflakes was 4 times larger than that for unrimed snowflakes (and $\beta$ was similar for both rimed and unrimed snowflakes). Since there is no observation to indicate $A_{\max }$, it can be approximated as the area of a circle having the same $D\left(A_{\text {sphere }}\right)$; but since graupel is not perfectly spherical, $A_{\max }$ can be better estimated as a fraction of $A_{\text {sphere: }}: A_{\max }=k A_{\text {sphere }}$, where $k$ is correction factor. Heymsfield (1978) analyzed graupel particles in northeastern Colorado, and found that their aspect ratio does not exceed 0.8 . Using this value, JH15 showed good agreement between their model and observational data from a wind tunnel. Based on such analysis, $k$ is equal to 0.8 . Further observational data are needed to determine the value of $A_{\max }$ more accurately.

So far, we discussed the phase 1 of riming growth (before the formation of graupel), where $m$ and $A$ increases while $D$ and therefore $\beta$ and $\delta$ are conserved. Once the graupel stage is attained, phase 2 of riming starts and the graupel continues to grow through riming, and a different methodology is required to describe riming growth at this growth stage, because graupel $D$ increases by riming. Once $m=m_{\max }$, then a graupel bulk density is defined as follows:

$\rho_{\mathrm{g}}=\frac{m_{\max }}{V_{\mathrm{g}}}$,

where $V_{\mathrm{g}}=(\pi / 6) D_{\mathrm{g}}^{3}$ and $D_{\mathrm{g}}$ is graupel $D$ when $m=m_{\max }$. For subsequent riming growth, $\rho_{\mathrm{g}}$ remains constant. For this 
growth stage, riming does increase $D$ and $A$, which are determined as a function of riming as follows:

$$
D=\left(\frac{6 m}{\pi \rho_{\mathrm{g}}}\right)^{\frac{1}{3}},
$$

where $m$ is calculated as described in Sect. 6. As before, for a given $D, \gamma=A / D^{\delta}$, and in this way riming growth is treated for all conditions.

\subsubsection{Columnar ice crystals}

Figure $4 \mathrm{~b}$ represents $m_{\mathrm{r}} / m_{\mathrm{u}}$ between graupel (R $4 \mathrm{~b}$ and $\mathrm{R} 4 \mathrm{c}$ ) and unrimed columnar crystals (N1e and N2c) in order to determine $m_{\max }$ for columnar crystals (initial graupel at the end of phase 1). Relatively small variability of $m_{\mathrm{r}} / m_{\mathrm{u}}$ (between 1.6 and 3) is found for $D<1400 \mu \mathrm{m}$, with larger variability (from 1.4 to 9.4) found for larger ice particles, with the weighted average of $m_{\mathrm{r}} / m_{\mathrm{u}}$ equal to 2.4 , and therefore $m_{\max } \approx 2.4 \times m_{\mathrm{u}}$. The higher variability for $D>1400 \mu \mathrm{m}$ is likely due to a single graupel particle per size bin. Based on the SCPP dataset, we showed that $D$ and $\beta$ are constants during the phase 1 of riming, and since initial graupel mass is 2.4 times larger than unrimed column mass, these mean that graupel density is $\sim 2.4$ times larger than unrimed column density.

\subsection{Testing the Baker and Lawson (2006) $m-A$ expression with unrimed dendrites}

Some of the data shown in Fig. 2 describes an experiment investigating the ability of the Baker and Lawson (2006; hereafter BL06) $m-A$ power law to reproduce the masses of unrimed dendrites that presumably have relatively low area ratios (the ratio of the actual ice particle projected area to the area of a circle having a diameter equal to $D$ ). A study by Avramov et al. (2011) found that this power law overestimated the masses of low-density dendrites (P1b), high-density dendrites (P1c), and low-density dendrite aggregates, but that the BL06 power law yielded masses consistent with high-density dendrite aggregates at commonly observed sizes. It is important to understand the potential limitations of this power law for dendrites due to their abundance in Arctic mixed-phase clouds and for the modeling of these clouds. BL06 used a subset of SCPP data (e.g., 865 ice particles), of which 550 were identifiable, and $36 \%$ of such identifiable particles were moderately or heavily rimed. They then developed software to calculate ice particle projected area from their magnified images. Thereafter, they calculated a $m-A$ power law expression. Since BL06 used only a subset of the SCPP data to produce a $m-A$ relationship (i.e., not a $m-D$ relationship), comparison of their work and our study is meaningful. Unfortunately, there were only seven unrimed and two lightly rimed dendrites in the BL06 dataset to investigate this finding. These are represented in Fig. 2 by green circles; their masses were calculated from the BL06 $m-A$ expression using their measured projected areas. For $D<1.4 \mathrm{~mm}$, the BL06 unrimed dendrite masses are consistent with the unrimed dendrite masses from all SCPP data evaluated in this study (e.g., are within $\pm 1 \sigma$ of mean $m$ for each size bin), but at larger sizes the BL06 unrimed dendrite masses conform with rimed dendrite masses evaluated in this study. This suggests that for $D>1.4 \mathrm{~mm}$, the BL06 $m-A$ expression might overestimate the masses of unrimed dendrites by about a factor of 2 . This is broadly consistent with Avramov et al. (2011) for the size range considered. However, there is insufficient data here to draw any firm conclusions.

Although $A$ is more strongly correlated with ice particle $m$ than $D$ is (based on BL06), inferring $m$ or volume from a 2-D measurement is still ambiguous since different crystal habits exhibit different degrees of ice thickness or volume for a given $A$. Thus, the BL06 $m-A$ expression is not expected to be universally valid for all ice crystal habits. On the other hand, when applied to $A$ measurements in cirrus clouds, it yields ice particle mass estimates that are very consistent with two other studies that estimated $m-D$ expressions for cirrus clouds (Heymsfield et al., 2010; Cotton et al., 2013), as described in Sect. 3. In addition, a comparison with a cold-habit SCPP dataset provided additional evidence that the BL06 $m-A$ expression yields masses appropriate for ice particles found in cirrus clouds. It also yields masses that are very consistent with the mean masses obtained for all ice particles sampled during the SCPP, indicating that the BL06 $m-A$ expression appears to be representative of ice particle masses characteristic of Sierra Nevada snow storms. As explained by EM16 and references therein, there is only about a $20 \%$ difference between IWCs calculated from PSD using the BL06 $m-A$ power law and collocated direct measurements of IWC in tropical regions; however, such differences can be as high as $100 \%$ in polar regions.

\section{Collision efficiencies}

As mentioned in Sect. 1.2, there is a lack of practical methods in the literature for computing $E_{\mathrm{c}}$ for plates, columns, and graupel. In this section, equations are provided that calculate $E_{\mathrm{c}}$ for hexagonal plates and hexagonal columns, based on the data of WJ00. Such equations can be used in cloud and climate models to treat the riming process.

\subsection{Hexagonal plates}

The numerical study of WJ00 is valid for unsteady flow, hexagonal ice plates with $1<\operatorname{Re}<120$ and $160 \mu \mathrm{m}<D<1700 \mu \mathrm{m}$, and water droplets having diameter $d$ between 1 and $100 \mu \mathrm{m}$. Re for hexagonal plates is calculated based on $D$ (e.g., $R e_{\text {plates }}=D V / \varepsilon$, where $\varepsilon$ is kinematic viscosity). Since there is not sufficient agreement 
between the historical $\mathrm{H} 80$ relationship and the data of WJ00, we provided best fits to the data of WJ00 that has the form of the following:

$$
E_{\mathrm{c}}=\left\{\begin{array}{l}
\left(0.787 K^{0.988}\right)(0.263 \ln R e-0.264) \\
0.01 \leq K \leq 0.35 \& 2<R e \leq 120 \\
(0.7475 \log K+0.620)(0.263 \ln R e-0.264) \\
0.35<K \leq K_{\text {thres }} \& 2<R e \leq 120 \\
\sqrt{1-\frac{1}{5}\left[\log \left(\frac{K}{K_{\text {crit }}}\right)-\sqrt{5}\right]^{2}}, \\
K_{\text {thres }}<K<35 \quad \& \quad 1 \leq R e \leq 120
\end{array}\right.
$$

where $K$ is a mixed Froude number of the system of water drop-ice particle, and is calculated as follows:

$K=\frac{2(V-v) v}{D g}$,

where $v$ is water-drop fall speed, and $g$ is gravitational acceleration. Since cloud water drops are in the Stokes regime, $v$ is calculated as the Stokes fall speed (e.g., $v=g\left(\rho_{\mathrm{W}}-\right.$ $\left.\rho_{\mathrm{a}}\right) d^{2} / 18 \mu$, where $\rho_{\mathrm{w}}$ is water density, $\rho_{\mathrm{a}}$ is air density, and $\mu$ is dynamic viscosity), and $K$ is the same as the Stokes number in this flow regime. $K_{\text {crit }}$ is the critical value of $K$ (where $E_{\mathrm{c}}$ equals 0 in the third line in Eq. 15) and is expressed as a function of ice particle $R e$ :

$K_{\text {crit }}=\left\{\begin{array}{ll}1.250 R e^{-0.350}, & 1<R e \leq 10 \\ 1.072 R e^{-0.301}, & 10<R e \leq 40 \\ 0.356 R e^{-0.003}, & 40<R e \leq 120\end{array}\right.$,

Based on Eq. (15), $E_{\mathrm{c}}$ in the third line is physically meaningful only when $K \geq K_{\text {crit }}$. When $K<K_{\text {crit }}, E_{\text {c }}$ in the third is imaginary and must be set to zero in order to avoid errors. $K_{\text {thres }}$ is the threshold of $K$ between small and large cloud droplets, and is calculated as $K_{\text {thres }}=-5.07 \times 10^{-10} R e^{5}+$ $1.73 \times 10^{-7} R e^{4}-2.17 \times 10^{-5} R e^{3}+0.0013 R e^{2}-0.037 R e+$ 0.8355 , and has values between 0.4 and 0.7 . Alternatively, it can be calculated for a desired $R e$ by equating $E_{\mathrm{c}}$ from the second line with $E_{\mathrm{c}}$ from the third line in Eq. (15) (e.g., finding the intersection of curves defined by the second and the third lines of Eq. 15) to avoid any discontinuity. The third line in Eq. (15) is an ellipse fit similar to H80 equation, but such a fit cannot represent finite values of $E_{\mathrm{c}}$ for small drops (when $K<K_{\text {thres }}$ ), and therefore this ellipse fit is not valid for small drops. To overcome this issue, curve fits are developed (the first and second lines in Eq. 15) similar to Mitchell (1995; hereafter M95). M95 provided curve fits to experimental $E_{\mathrm{c}}$ data described in ST73, K74 and Murakami et al. (1985) that showed slight sensitivity to $R e$. Here, those equations are modified and additional terms are employed to account for the $R e$ dependence of $E_{\mathrm{c}}$ for small droplets, based on the data of WJ00.
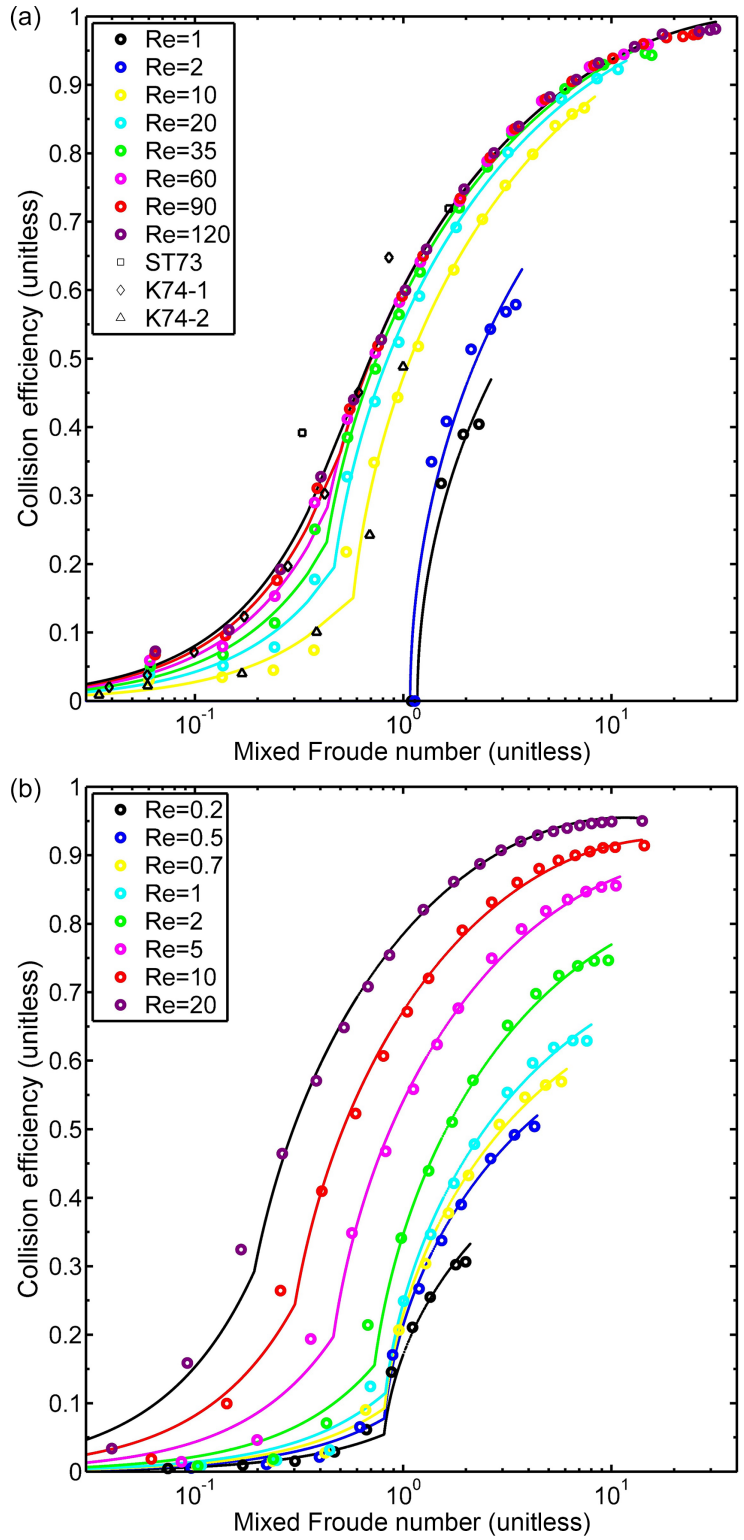

Figure 5. (a) Collision efficiency for hexagonal plates as a function of the mixed Froude number. Circles show the data of WJ00 based on numerical calculations, and curves show the best fits to this data for various values of $R e$. Also displayed are experimental data of ST73 for $R e=97$ (squares), K74 for $200 \leq R e \leq 640$ (diamonds), and K74 for $10 \leq R e \leq 35$ (triangles). (b) Same as (a), but for hexagonal columns and no experimental data.

The resulting curve fits for $E_{\mathrm{c}}$ (Fig. 5a) show that the provided equations can represent the data of WJ00 very well in various ranges of $K$ and $R e$. The percent error in $E_{\mathrm{c}}$ between curve fits and WJ00 data has a mean value of $6.65 \%$ with standard deviation of $3.67 \%$ for all $R e$ and $K$. For a given $K, E_{\mathrm{c}}$ for planar crystals increases with an increase in $R e$ because of the increase in the plate's fall speed. In addition, $E_{\mathrm{c}}$ has a slight sensitivity to $R e$ for $R e \geq 60 . E_{\mathrm{c}}$ for small 
$R e(R e \leq 2)$ appears to have a different pattern than that for larger $R e$, since $E_{\mathrm{c}}$ has zero values for small water drops $(K \leq 1)$. This implies that smaller ice particles that have sizes slightly larger than the $D_{\text {thres }}$ are incapable of collecting the smaller drops. For a given $R e, E_{\mathrm{c}}$ increases with increasing $K$, associated with an increase in droplet diameter, but it does not exceed a value of unity. For comparison, historical experiments by ST73 and K74 are also shown in this graph. K74 data for $10 \leq R e \leq 35$ is in good agreement with the curve fit for $R e=10$. Values of $E_{\mathrm{c}}$ from K74 for $200 \leq R e \leq 640$ are slightly lower than curve fit for $R e=120$. This does not seem to be a discrepancy, because it is observed from the curve fits (based on WJ00) that $E_{\mathrm{c}}$ is not sensitive to $R e$ when $R e \geq 60$. This is also observed in K74 for large $R e$ (their Fig. 14). $E_{\mathrm{c}}$ from ST73 for $R e=97$ is in good agreement with the curve fit for $K \sim 1.5$, but is larger than the curve fit for $K \sim 0.3$. It is noteworthy to explain the shortcomings of these experiments, as mentioned by Pruppacher and Klett (1997). For the experiment of $\mathrm{K} 74$, when $R e>100$, the flow is unsteady and leads to the eddy shedding and formation of wakes at the top of the particle, which increases the uncertainty in fall speed. For the study of ST73, there is an extra problem: the air stream speed was not in agreement with the fall speed that the fixed collectors would have, if they were to fall freely.

For $K>1.0$, M95 modified the relationship by Langmuir (1948) for $E_{\mathrm{c}}$ between spherical water raindrops and cloud droplets, and provided an expression as $E_{\mathrm{c}}=(K+$ $1.1)^{2} /(K+1.6)^{2}$. However, this relationship underestimates the best fits to the data of WJ00 (figure not shown). This confirms the findings of von Blohn et al. (2009) who observed smaller $E_{\mathrm{c}}$ for raindrops relative to graupel, and highlights the need for using $E_{\mathrm{c}}$ for ice particles with realistic shapes and avoiding $E_{\mathrm{c}}$ surrogates suitable for spherical raindrops.

Note that Eqs. (15)-(17) are derived for the range over which the data of WJ00 is valid (e.g., $1<R e<120$ ), and they should not be used for extrapolation to $R e$ values larger or smaller than this range. Since $R e<1$ corresponds to ice particles smaller than $D_{\text {thres }}$, it is justified to assume that $E_{\mathrm{c}}=0$ in this $R e$ range. When considering the range $R e>120$, values of $E_{\mathrm{c}}$ for $R e=120$ should be used; this is reasonable based on the experiments of K74 for $200<R e<640$, and the theoretical study of WJ00 for $60 \leq R e \leq 120$.

\subsection{Hexagonal columns}

H80 and M95 did not provide any $E_{\mathrm{c}}$ equation for columnar crystals. To the best of our knowledge, there is not any practical $E_{\mathrm{c}}$ equation for such crystals in the literature, suitable for use in cloud-resolving models, except for the study of $\mathrm{JH} 15$ that calculated $E_{\mathrm{c}}$ for prolate spheroids based on their aspect ratio. In addition to hexagonal plates, WJ00 studied $E_{\mathrm{c}}$ between hexagonal columns (with width $w$ between 47 and $292.8 \mu \mathrm{m}$, length $l$ between 67.1 and $2440 \mu \mathrm{m}$ and $0.2<R e<20)$ and water drops of $1 \mu \mathrm{m}<d<100 \mu \mathrm{m}$. Note that WJ00 calculated $R e$ for columns in a different way than was done for plates. Re for columns was calculated from their width, whereas $R e$ for plates was computed from $D$ (e.g., $R e_{\text {columns }}=w V / \varepsilon$ ). If the values of $R e$ were calculated from the column maximum dimension, they would have values comparable to those for plates. In formulating $E_{\mathrm{c}}$ for columns, we have followed the Re convention of WJ00. Similar to hexagonal plates, we provide the best fits to the data of WJ00 for hexagonal columns:

$$
E_{\mathrm{c}}=\left\{\begin{array}{l}
\left(0.787 K^{0.988}\right)\left(-0.0121 R e^{2}+0.1297 R e+0.0598\right), \\
0.01 \leq K \leq K_{\text {thres }} \& \quad 0.2 \leq R e \leq 3 \\
\left(0.787 K^{0.988}\right)\left(-0.0005 R e^{2}+0.1028 R e+0.0359\right), \\
0.01 \leq K \leq K_{\text {thres } \quad \& \quad 3<R e \leq 20}, \\
r \sqrt{1-\frac{1}{3.5}\left[\log \left(\frac{K}{K_{\text {crit }}}\right)-\sqrt{3.5}\right]^{2}}, \\
K_{\text {thres }}<K<20 \quad \& \quad 0.2 \leq R e \leq 20
\end{array}\right.
$$

where $K$ is calculated from Eq. (16), and $K_{\text {crit }}$ is calculated as follows.

$K_{\text {crit }}=\left\{\begin{array}{lr}0.7797 R e^{-0.009}, & 0.2 \leq R e \leq 1.7 \\ 1.0916 R e^{-0.635}, & 1.7<R e \leq 20\end{array}\right.$

Also, $r$ is a parameter related to the major radius of the ellipse fit and is determined as follows.

$r=\left\{\begin{array}{lc}0.8025 R e^{0.0604}, & 0.2 \leq R e \leq 1.7 \\ 0.7422 R e^{0.2111}, & 1.7<R e \leq 20\end{array}\right.$,

and $K_{\text {thres }}$ is calculated as follows:

$K_{\text {thres }}=\left\{\begin{array}{l}0.0251 R e^{2}-0.0144 R e+0.811 \\ 0.2 \leq R e \leq 2 \\ -0.0003 R e^{3}+0.0124 R e^{2}-0.1634 R e+1.0075 \\ 2<R e \leq 20\end{array}\right.$

The results are shown in Fig. 5b. Similar to hexagonal plates, the curve fits are able to represent the data of WJ00 very well over various ranges of $K$ and $R e$. The percent error in $E_{\mathrm{c}}$ between the curve fits and the WJ00 data has a mean value of $10.28 \%$ with a standard deviation of $5.81 \%$ for all $R e$ and $K$. There are no experimental estimates of $E_{\mathrm{c}}$ for hexagonal columns in the literature for comparison. For a given $K, E_{\mathrm{c}}$ of columnar ice crystals increases with increasing $R e$ (due to the increase in fall speed). For a given $R e, E_{\mathrm{c}}$ increases with increasing $K$ (because of increasing droplet diameter), but it does not exceed 0.95 . Unlike plates, the increase in $R e$ does not decrease the sensitivity of $E_{\mathrm{c}}$ to $R e$. 
Again, Eqs. (18)-(21) should not be used for $R e<0.2$ and $R e>20$. In the range $R e<0.2$, the column size does not exceed the $D_{\text {thres }}$, and therefore $E_{\mathrm{c}}=0$. For $R e>20$, values of $E_{\mathrm{c}}$ are unknown, but we suggest using $E_{\mathrm{c}}$ for $R e=20$ as a conservative underestimate of $E_{\mathrm{c}}$.

\section{Mass growth rate by riming}

In Sect. 4, the dependence of $\alpha$ on IWC was explained. Unrimed IWC can be derived from $\alpha$ and $\beta$ pertaining to unrimed ice crystals (see EM16). The riming rate for a single ice particle of size $D$ can be calculated by using the definition of riming mass growth rate, similar to Heymsfield (1982), M95, and JH15:

$$
\begin{aligned}
& \left(\frac{\mathrm{d} m}{\mathrm{~d} t}\right)_{\text {riming }}=\int_{0}^{d_{\max }} A_{\mathrm{g}}(D, d) \mid V(D) \\
& -v(d) \mid E(D, d) m(d) n(d) \mathrm{d} d,
\end{aligned}
$$

where $t$ is time, $d$ is diameter of a cloud droplet, $A_{\mathrm{g}}(D, d)$ is the geometrical cross-section area of the ice particlecloud droplet collection kernel, $E(D, d)$ is collection efficiency between the cloud droplet and ice particle, $m(d)$ is the cloud droplet mass, $n(d)$ is the cloud droplet number distribution, and $d_{\max }$ is diameter of the largest cloud droplet. Note that the cloud droplet sedimentation velocity $v(d)$ is negligible compared to the ice particle fall speed $V(D)$ and was neglected in the similar equation by Heymsfield (1982), M95, and Zhang et al. (2014). Zhang et al. (2014) used a different equation, which has the form of $\mathrm{d} m / \mathrm{d} t=A(D) V(D) E(D) \mathrm{LWC}$, where LWC is equal to $\int_{0}^{d_{\max }} m(d) n(d) \mathrm{d} d$. For this equation, the riming rate is not sensitive to the droplet distribution.

Based on the observations of Locatelli and Hobbs (1974), many cloud and climate models use a $V-D$ power law to predict ice mass sedimentation rates $\left(V=a_{v} D^{b_{v}}\right.$, with constant $a_{v}$ and $b_{v}$ for each specific particle habit; Rutledge and Hobbs, 1984; Ferrier, 1994; Fowler et al., 1996; Pinski et al., 1998; Morrison and Gettelman, 2008; Gettelman and Morrison, 2015). However, such a relationship cannot represent the evolution of ice particle size and shape, and is often inconsistent with the realistic dependence of $V$ on the ice particle $m / A$ ratio. This increases uncertainty in the microphysical and optical properties of such models. To overcome this issue, M96 introduced a method that derives $V$ by using $m$ and $A$, and also by a power law for the Best number $(X)$ and $R e$ relationship ( $R e=A_{x} X^{B_{x}}$, where $A_{x}$ and $B_{x}$ are constant coefficients in specific ranges of $X$ ). In this method, the $V$ calculation depends on the $m / A$ ratio. Mitchell and Heymsfield (2005) followed the same method, but they used a $R e-X$ power law with variable coefficients ( $A$ and $B$ are not constant anymore) to produce a smooth transition between different flow regimes. Such an approach is shown to represent the evolution of $V$ realistically (MG08; Morrison and Grabowski, 2010; JH15; Morrison and Milbrandt, 2015). In addition, Heymsfield and Westbrook (2010) developed an alternative method to improve M96 method, and calculated $X$ as a function of $m / A_{\mathrm{r}}$ ratio, where $A_{\mathrm{r}}$ is area ratio (defined as the ratio of ice particle projected area to the projected area of a circumscribed circle around the particle; see Eq. 15 in Erfani and Mitchell, 2016).

Since the contribution of the cloud droplet projected area to $A_{g}(D, d)$ is negligible, $A_{g}(D, d)$ can be approximated as the maximum ice particle cross-section area projected normal to the air flow. Ice particles fall with their major axis perpendicular to the fall direction, therefore $A_{g}(D, d)$ is approximated as the ice particle $A$, which is calculated in Sect. 4.2. The $m(d)$ is calculated from spherical geometry as $m(d)=\pi d^{3} \rho_{\mathrm{w}} / 6 . E(D, d)$ is equal to $E_{\mathrm{c}} E_{\mathrm{s}}$ where $E_{\mathrm{c}}$ was discussed in Sect. 5, and $E_{\mathrm{S}}$ is the sticking efficiency (fraction of the water droplets that stick to the ice particle after collision), and is presumed to be unity since supercooled cloud droplets freeze and bond to an ice particle upon collision. Conditions under which $E_{\mathrm{S}}$ may be less than unity are addressed in Pruppacher and Klett (1997). It is noteworthy that by using the above calculations, riming growth will be represented in a self-consistent, gradual, and continuous way. Based on the explanations in this section, Eq. (22) can be reduced to the following:

$$
\left(\frac{\mathrm{d} m}{\mathrm{~d} t}\right)_{\text {riming }}=A(D) V(D) \int_{0}^{d_{\max }} E(D, d) m(d) n(d) \mathrm{d} d .
$$

Differentiating Eq. (1) with respect to $t$ corresponds to $\mathrm{d} m / \mathrm{d} t=D^{\beta} d \alpha / \mathrm{d} t+\alpha \beta D^{\beta-1} \mathrm{~d} D / \mathrm{d} t$, but the second term on the RHS should be relatively small (riming has little impact on $D$ prior to graupel formation). Therefore, to a first approximation, the following applies:

$$
\left(\frac{\mathrm{d} \alpha}{\mathrm{d} t}\right)_{\text {riming }}=\frac{1}{D^{\beta}}\left(\frac{\mathrm{d} m}{\mathrm{~d} t}\right)_{\text {riming }},
$$

and together with Eq. (23), a change in $\alpha$ due to riming can be determined. Since $D$ and $\beta$ do not change by riming, $\mathrm{d} \alpha / \mathrm{d} t$ is linearly proportional to $\mathrm{d} m / \mathrm{d} t$.

Figure 6 shows $\mathrm{d} m / \mathrm{d} t$ calculated from Eq. (23) for hexagonal ice plates and hexagonal columns for different values of LWC and droplet median-mass diameter (MMD: the droplet diameter that divides the droplet PSD mass into equal parts). $E_{\mathrm{c}}$ is calculated from Eqs. (15) and (18) for hexagonal plates and hexagonal columns, respectively, and a sub-exponential PSD is assumed for cloud droplets that has the following form:

$n(d)=N_{o} d^{v} \exp (-\lambda d)$, 

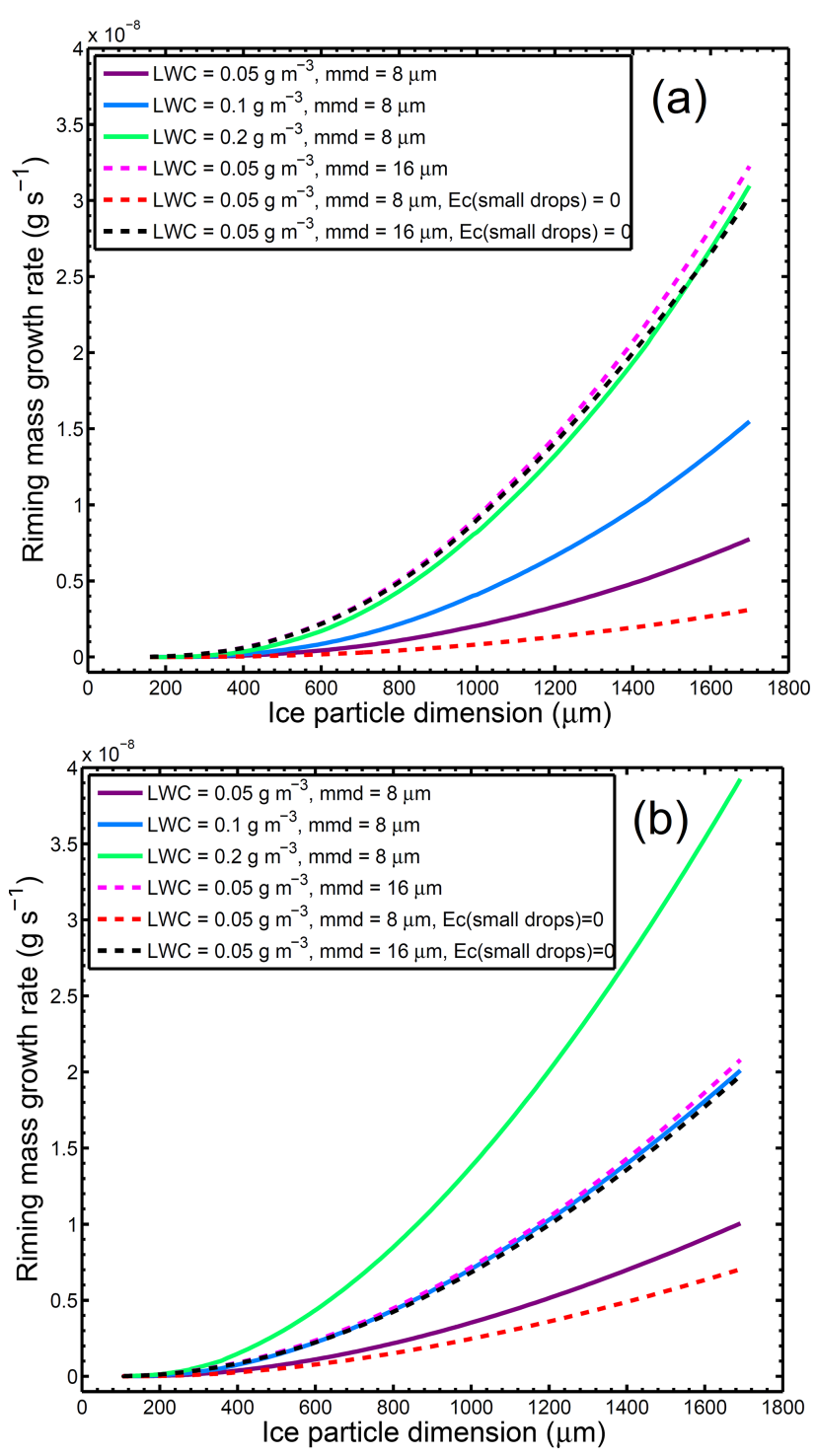

Figure 6. Riming mass growth rate versus ice particle maximum dimension $D$ for various LWCs $\left(0.05,0.1\right.$, and $\left.0.2 \mathrm{~g} \mathrm{~m}^{-3}\right)$ and different droplet median-mass diameters $(8$ and $16 \mu \mathrm{m})$ for (a) hexagonal plates and (b) hexagonal columns. Additional curves (dashed red and dashed black curves) are produced by assuming that $E_{\mathrm{c}}$ conforms to the ellipse curves and is zero for smaller droplets.

where $\lambda$ is the PSD slope parameter, $v$ is the PSD dispersion parameter and $N_{o}$ is intercept parameter. M95 used observational droplet spectra from Storm Peak lab (Steamboat Springs, Colorado, USA), and calculated various PSD parameters: $v=9, \lambda=(v+1) / \bar{d}$, and $N_{o}=4 \times$ $10^{4} L W C / \rho_{\mathrm{w}} \bar{d}^{13}$, where $\bar{d}$ is droplet mean diameter, and is related to MMD as MMD $=1.26 \bar{d}$ for this dataset. Note that all variables are in units of cgs. It is seen in Fig. 6a that $\mathrm{d} m / \mathrm{d} t$ for riming increases with increasing ice particle $D$. The $\mathrm{d} m / \mathrm{d} t$ is linearly proportional to LWC when MMD and $D$ are constant. In addition, when LWC is constant, dou- bling MMD (from 8 to $16 \mu \mathrm{m}$ ) leads to a quadrupling of $\mathrm{d} m / \mathrm{d} t$. One important feature is the contribution of small droplets $(d<10 \mu \mathrm{m})$ to $\mathrm{d} m / \mathrm{d} t$, when $K<0.7$ and $E_{\mathrm{c}}<0.3$. It is seen in this figure that when MMD is relatively small $(=8 \mu \mathrm{m})$, ignoring such small droplets results in values of $(\mathrm{d} m / \mathrm{d} t)_{\text {riming }}$ at the largest crystal sizes that are $\sim 40$ (for plates) and $\sim 70 \%$ (for columns) of those obtained when all droplets are included. That is, small droplets contribute about 60 and $30 \%$, respectively, to the $(\mathrm{d} m / \mathrm{d} t)_{\text {riming values }}$ at the largest sizes. This surprising contribution from small droplets is partly due to half of the LWC being associated with $d<8 \mu \mathrm{m}$. However, when MMD is larger $(=16 \mu \mathrm{m})$, the contribution from small droplets is only $\sim 5 \%$. The sizedependence of $\mathrm{d} m / \mathrm{d} t$ for hexagonal columns (Fig. 6b) shows that $\mathrm{d} m / \mathrm{d} t$ for columns is larger than that for hexagonal plates for a specific crystal size when droplet MMD is $8 \mu \mathrm{m}$, partly because columns fall faster than plates (see Fig. 6 in M96) and partly due to higher $E_{\mathrm{c}}$ for columns encountering larger droplets. Moreover, when LWC is constant, doubling MMD (from 8 to $16 \mu \mathrm{m}$ ) leads to at least a doubling of $\mathrm{d} m / \mathrm{d} t$ (greater for plates).

The collection kernel $\left(K_{\mathrm{c}}\right)$ can be calculated as $A(D) V(D) E(D, d)$, which is alternatively equal to $\mathrm{d} m / \mathrm{d} t$ divided by the ice particle mass due to riming (see Eq. 23). MG08 approximated this variable by using simple assumptions, and found that it is proportional to $D^{2}$. Here, we showed by more accurate analysis that $K_{c}$ has a form of a second-order polynomial fit, and is represented for $\mathrm{MMD}=8 \mu \mathrm{m}$ and hexagonal plates by $K_{c}=7 \times 10^{-6} D^{2}$ $0.0002 D+0.0008$.

\section{Conclusions}

In most atmospheric models, riming is treated as an abrupt change between precipitation classes: from snow to graupel, which occurs at an arbitrary threshold size. Such parameterizations are not realistic and lead to uncertainty in the simulation of snowfall. In this study, a combination of various empirical and theoretical approaches is utilized to shed light on the riming process. SCPP ground-based measurements of $m$ and $D$ for rimed and unrimed ice particles are used in this study; such particles represent ice clouds for $-40^{\circ} \mathrm{C}<T<0^{\circ} \mathrm{C}$. The findings presented here suggest a fundamental shift in our way of representing ice particle mass and projected area in atmospheric models for riming. It is common in most models to assume that riming increases $\beta$ (Eq. 1) from values of $\sim 2$ (for dendrites) to values of $\sim 3$ (for graupel). However, we showed that this assumption is not supported by observations. To a good approximation under most conditions, riming does not increase (or decrease) $\beta$ and $D$ in an $m-D$ power law and the treatment of riming is simplified, with riming increasing only $\alpha$ during the phase 1 of riming (before the formation of graupel). To represent unrimed particles in frontal clouds, one could enlist the poly- 
nomial fit for synoptic ice clouds $\left(-40^{\circ} \mathrm{C}<T<-20^{\circ} \mathrm{C}\right.$, see EM16) but adjust this equation to conform to the observed power laws for unrimed dendrites. To treat riming for dendrites, this fit equation could be multiplied by the riming fraction $m_{\mathrm{r}} / m_{\mathrm{u}}$ or alternatively IWC/IWC $\mathrm{u}$. A similar strategy could be adopted for other ice particle shapes or shape mixtures in frontal clouds, as is done for columnar particles in this study. By using this method, there is no discontinuity in the growth of $m$ and $A$; rather, the particles grow gradually during the riming process. Phase 2 of riming starts when graupel with quasi-spherical shape forms. In this phase, the increase in $m$ and $A$ causes an increase in $D$.

It is straightforward for models with multiple ice categories to utilize our new method. This can be done by describing riming growth as two phases and removing the autoconversion process. Phase 1 simulates riming growth from an unrimed ice crystal to the onset of graupel formation. In this phase, ice particle mass and projected area gradually increase, but size is unchanged (Eqs. 6-11). Phase 2 represents graupel growth. In this phase, the shape is unchanged, but mass, projected area, and size gradually increase (Eqs. 1214). By using the method introduced in this study, models may still use multiple categories (e.g., ice crystal, rimed particle, graupel), but within each category the rimed mass fraction can gradually increase, thus preventing an abrupt change in ice particle attributes between categories.

Prior to this work, there was only one rigorous practical method for calculating the droplet size-dependence of $E_{\mathrm{c}}$ for use in models. As described in JH15, this method when applied to prolate spheroids modified the equation from Beard and Grover (1974) for spherical raindrops in steady flow, and calculated $E_{\mathrm{c}}$ between a cloud droplet and a prolate spheroid based on the spheroid aspect ratio. Many cloudresolving models use the $\mathrm{H} 80$ equation to calculate $E_{\mathrm{c}}$ for planar crystals, but this equation has important drawbacks inherited from the early numerical studies (See Sect. 1.2). To solve this problem, new equations for the calculation of $E_{\mathrm{c}}$ are developed based on the numerical study of WJ00 for both hexagonal plates and hexagonal columns that account for dependence of $E_{\mathrm{c}}$ on cloud droplet $d$ and ice particle $D$ in non-steady flow. In the future, this treatment of the riming process will be employed in a new snow growth model that predicts the vertical evolution of ice particle size spectra, mass, projected area, fall speed, and snowfall rate in terms of the growth processes of vapor diffusion, aggregation and riming. These results will be compared with airborne measurements from two spiral descents.

\section{List of symbols and their definitions}

$a_{v}$ prefactor in fall speed-dimension power law $A$ projected area

$A_{\mathrm{g}}$ geometrical cross-section area

$A_{\text {max }}$ graupel projected area
$A_{\mathrm{r}}$ projected area ratio

$A_{x}$ prefactor in Reynolds number-Best number power law

$b_{v}$ exponent in fall speed-dimension power law

$B_{x}$ exponent in Reynolds number-Best number power law

$d$ water drop diameter

$\bar{d}$ drop mean diameter

$D$ maximum dimension of ice particle

$D_{\mathrm{g}}$ maximum dimension of initial graupel (at the end of phase 1 of riming)

$E$ collection efficiency

$E_{\mathrm{c}}$ collision efficiency

$E_{\mathrm{S}}$ sticking efficiency

$g$ gravitational constant

$k$ correction factor for graupel projected area

$K$ mixed Froude number

$K_{\text {crit }}$ critical value of mixed Froude number

$K_{\mathrm{c}}$ collection kernel

$K_{\text {thres }}$ threshold of $K$

$l$ length of columnar crystals

$m$ mass of ice particle

$m_{\mathrm{r}}$ rimed mass

$m_{\mathrm{u}}$ unrimed mass

$m_{\max }$ graupel mass

$m_{\text {mix }}$ mass of mixture of rimed and unrimed particles

$M_{\mathrm{f}}$ ice mass flux

$n$ number distribution

$N_{o}$ intercept parameter of a gamma PSD

$P$ air pressure

$r$ parameter related to the major radius of the ellipse fit

Re Reynolds number

$t$ time

$T$ temperature

$v$ terminal fall speed of water drop

$V$ terminal fall speed of ice particle

$V_{\mathrm{g}}$ volume of initial graupel (at the end of phase 1 of riming)

$V_{\mathrm{m}}$ mass-weighted terminal fall speed

$w$ width of columnar crystals

$X$ Best number

$\alpha$ prefactor in mass-dimension power law

$\beta$ exponent in mass-dimension power law

$\gamma$ prefactor in projected area-dimension power law

$\delta$ exponent in projected area-dimension power law

$\varepsilon$ kinematic viscosity

$\mu$ dynamic viscosity

$\lambda$ slope parameter of a gamma PSD

$v$ dispersion parameter of a gamma PSD

$\rho_{\mathrm{a}}$ air density

$\rho_{g}$ initial graupel bulk density (at the end of phase 1 of riming)

$\rho_{i}$ ice density

$\rho_{\mathrm{w}}$ water density 


\section{Data availability}

The SCPP data used in this study and associated software is freely available to interested researchers; those interested should contact the second author.

Competing interests. The authors declare that they have no conflict of interest.

Acknowledgements. This research was supported by the Office of Science (BER), US Department of Energy. We are grateful to Brad Baker for providing us with the measurements of ice particle projected areas that were used in BL06. We are also thankful to two anonymous reviewers for their constructive comments that improved the paper.

Edited by: M. Krämer

Reviewed by: E. Fontaine and one anonymous referee

\section{References}

Avramov, A., Ackerman, A. S., Fridlind, A. M., van Diedenhoven, B., Botta, G., Aydin, K., Verlinde, J., Korolev, A. V., Strapp, J. W., McFarquhar, G. M., Jackson, R., Brooks, S. D., Glen, A., and Wolde, M.: Toward ice formation closure in Arctic mixedphase boundary layer clouds during ISDAC, J. Geophys. Res., 116, D00T08, doi:10.1029/2011JD015910, 2011.

Baker, B. and Lawson, R. P.: Improvement in determination of ice water content from two-dimensional particle imagery, Part I: Image-to-mass relationships, J. Appl. Meteorol. Clim., 45, 12821290, 2006.

Beard, K. V. and Grover, S. N.: Numerical Collision Efficiencies for Small Raindrops Colliding with Micron Size Particles, J. Atmos. Sci., 31, 543-550, 1974.

Bruintjes, R. T., Heymsfield, A. J., and Krauss, T. W.: Examination of double-plate ice crystals and the initiation of precipitation in continental cumulus clouds, J. Atmos. Sci., 44, 1331-1349, 1987.

Cotton, R. J., Field, P. R., Ulanowski, Z., Kaye, P. H., Hirst, E., Greenaway, R. S., Crawford, I., Crosier, J., and Dorsey, J.: The effective density of small ice particles obtained from in situ aircraft observations of mid-latitude cirrus, Q. J. Roy. Meteorol. Soc., 139, 1923-1934, 2013.

Eidhammer, T., Morrison, H., Bansemer, A., Gettelman, A., and Heymsfield, A. J.: Comparison of ice cloud properties simulated by the Community Atmosphere Model (CAM5) with in-situ observations, Atmos. Chem. Phys., 14, 10103-10118, doi:10.5194/acp-14-10103-2014, 2014.

Erfani, E. and Mitchell, D. L.: Developing and bounding ice particle mass- and area-dimension expressions for use in atmospheric models and remote sensing, Atmos. Chem. Phys., 16, 43794400, doi:10.5194/acp-16-4379-2016, 2016.

Feng, D. and Grant, L.: Correlation of snow crystal habit, number flux and snowfall intensity from ground observations, Conf. on Cloud Physics, Amer. Meteor. Soc., Boston, Massachusetts, 485487, 1982.
Ferrier, B. S.: A Double-Moment Multiple-Phase Four-Class Bulk Ice Scheme, Part I: Description, J. Atmos. Sci., 51, 249-280, 1994.

Fontaine, E., Schwarzenboeck, A., Delanoë, J., Wobrock, W., Leroy, D., Dupuy, R., Gourbeyre, C., and Protat, A.: Constraining mass-diameter relations from hydrometeor images and cloud radar reflectivities in tropical continental and oceanic convective anvils, Atmos. Chem. Phys., 14, 11367-11392, doi:10.5194/acp14-11367-2014, 2014.

Fowler, L. D., Randall, D. A., and Rutledge, S. A.: Liquid and ice cloud microphysics in the CSU general circulation model, 1. Model description and simulated microphysical processes, J. Climate, 9, 489-529, 1996.

Fukuta, N. and Takahashi, T.: The growth of atmospheric ice crystals: A summary of findings in vertical supercooled cloud tunnel studies, J. Atmos. Sci., 56, 1963-1979, 1999.

Gettelman, A. and Morrison, H.: Advanced Two-Moment Bulk Microphysics for Global Models, Part I: Off-Line Tests and Comparison with Other Schemes, J. Climate, 28, 1268-1287, 2015.

Hall, W. D.: A Detailed Microphysical Model Within a TwoDimensional Dynamic Framework: Model Description and Preliminary Results, J. Atmos. Sci., 37, 2486-2507, 1980.

Harimaya, T.: Riming properties of snow crystals, J. Meteorol. Soc. Jpn., 53, 384-392, 1975.

Harimaya, T. and Sato, M.: Measurement of the riming amount on snowflakes, J. Fac. Sci., Hokkaido Univ., 8, 355-366, 1989.

Heymsfield, A. J.: A Comparative Study of the Rates of Development of Potential Graupel and Hail Embryos in High Plains Storms, J. Atmos. Sci., 39, 2867-2897, 1982.

Heymsfield, A. J.: Characteristics of graupel particles in northeastern Colorado cumulus congestus clouds, J. Atmos. Sci., 35, 284 295, 1978.

Heymsfield, A. J. and Miloshevich, L. M.: Homogeneous Ice Nucleation and Supercooled Liquid Water in Orographic Wave Clouds, J. Atmos. Sci., 50, 2335-2353, 1993.

Heymsfield, A. J., Schmitt, C., Bansemer, A., and Twohy, C. H.: Improved Representation of Ice Particle Masses Based on Observations in Natural Clouds, J. Atmos. Sci., 67, 3303-3318, 2010.

Heymsfield, A. J. and Westbrook, C. D.: Advances in the Estimation of Ice Particle Fall Speeds Using Laboratory and Field Measurements, J. Atmos. Sci., 67, 2469-2482, 2010.

Hobbs, P. V.: Organization and structure of clouds and precipitation on the mesoscale and microscale in cyclonic storms, Rev. Geophys. Space Phys., 16, 741-755, 1978.

Jensen, A. A. and Harrington, J. Y.: Modeling Ice Crystal Aspect Ratio Evolution during Riming: A Single-Particle Growth Model, J. Atmos. Sci., 72, 2569-2590, 2015.

Kajikawa, M.: On the collection efficiency of snow crystals for cloud droplets, J. Meteorol. Soc. Jpn., 52, 328-336, 1974.

Kalesse, H., Szyrmer, W., Kneifel, S., Kollias, P., and Luke, E.: Fingerprints of a riming event on cloud radar Doppler spectra: observations and modeling, Atmos. Chem. Phys., 16, 2997-3012, doi:10.5194/acp-16-2997-2016, 2016.

Khain, A., Pokrovsky, A., and Sednev, I.: Some effects of cloudaerosol interaction on cloud microphysics structure and precipitation formation: numerical experiments with a spectral microphysics cloud ensemble model, Atmos. Res., 52, 195-220, 1999. 
Langmuir, I.: The production of rain by a chain reaction in cumulus clouds at temperatures above freezing, J. Meteorol., 5, 175-192, 1948.

Locatelli, J. D. and Hobbs, P. V.: Fall speeds and masses of solid precipitation particles, J. Geophys. Res., 79, 2185-2197, 1974.

Magono, C. and Lee, C. W.: Meteorological Classification of Natural Snow Crystals, J. Fac. Sci., Hokkaido University, 7, 4, 1966.

Matejka, T. J., Houze, R. A., and Hobbs, P. V.: Microphysics and dynamics of clouds associated with mesoscale rainbands in extratropical cyclones, Q. J. Roy. Meteorol. Soc., 106, 29-56, 1980.

Mitchell, D. L.: An analytical model predicting the evolution of ice particle size distributions, $\mathrm{PhD}$, University of Nevada-Reno, $\mathrm{PhD}$ Dissertation, 181 pp., 1995.

Mitchell, D. L.: Evolution of snow-size spectra in cyclonic storms, 1. snow growth by vapor-deposition and aggregation, J. Atmos. Sci., 45, 3431-3452, 1988.

Mitchell, D. L.: Use of mass- and area-dimensional power laws for determining precipitation particle terminal velocities, J. Atmos. Sci., 53, 1710-1723, 1996.

Mitchell, D. L. and d'Entremont, R. P.: Satellite retrieval of the liquid water fraction in tropical clouds between -20 and $-38^{\circ} \mathrm{C}$, Atmos. Meas. Tech., 5, 1683-1698, doi:10.5194/amt-5-16832012, 2012.

Mitchell, D. L. and Erfani, E.: Developing and bounding ice particle mass- and area-dimension expressions for use in climate models and remote sensing, AMS Cloud Physics Conference, Boston, MA, July, 2014.

Mitchell, D. L. and Heymsfield, A. J.: Refinements in the treatment of ice particle terminal velocities, highlighting aggregates, J. Atmos. Sci., 62, 1637-1644, 2005.

Mitchell, D. L., Huggins, A., and Grubisic, V.: A new snow growth model with application to radar precipitation estimates, Atmos. Res., 82, 2-18, 2006.

Mitchell, D. L., Zhang, R., and Pitter, R. L.: Mass-dimensional relationships for ice particles and the influence of riming on snowfall rates, J. Appl. Meteorol., 29, 153-163, 1990.

Morrison, H. and Gettelman, A.: A new two-moment bulk stratiform cloud microphysics scheme in the community atmosphere model, version 3 (CAM3), Part I: Description and numerical tests, J. Climate, 21, 3642-3659, 2008.

Morrison, H. and Grabowski, W. W.: A novel approach for representing ice microphysics in models: Description and tests using a kinematic framework, J. Atmos. Sci., 65, 1528-1548, 2008.

Morrison, H. and Grabowski, W. W.: An Improved Representation of Rimed Snow and Conversion to Graupel in a Multicomponent Bin Microphysics Scheme, J. Atmos. Sci., 67, 1337-1360, 2010.

Morrison, H. and Milbrandt, J. A.: Parameterization of Cloud Microphysics Based on the Prediction of Bulk Ice Particle Properties, Part I: Scheme Description and Idealized Tests, J. Atmos. Sci., 72, 287-311, 2015.

Murakami, M., Kikuchi, K., and Magono, C.: Experiments on aerosol scavenging by natural snow crystals, Part I: Collection efficiencies of uncharged snow crystals for micron and submicron particles, J. Meteorol. Soc. Jpn., 63, 119-129, 1985.

Pflaum, J. C. and Pruppacher, H. R.: A Wind Tunnel Investigation of the Growth of Graupel Initiated from Frozen Drops, J. Atmos. Sci., 36, 680-689, 1979.
Pinsky, M., Khain, A., Rosenfeld, D., and Pokrovsky, A.: Comparison of collision velocity differences of drops and graupel particles in a very turbulent cloud, Atmos. Res., 49, 99-113, 1998.

Pitter, R. L.: A reexamination of riming on thin ice plates, J. Atmos. Sci., 34, 684-685, 1977.

Pitter, R. L. and Pruppacher, H. R.: A numerical investigation of collision efficiencies of simple ice plates colliding with supercooled water drops, J. Atmos. Sci., 31, 551-559, 1974.

Pruppacher, H. R. and Klett, J. D.: Microphysics of clouds and precipitation: 2nd Edn., Kluwer Academic Publishers, Dordrecht, the Netherlands, 1997.

Rasmussen, R. M. and Heymsfield, A. J.: A Generalized Form for Impact Velocities Used to Determine Graupel Accretional Densities, J. Atmos. Sci., 42, 2275-2279, 1985.

Reisin, T., Levin, Z., and Tzivion, S.: Rain production in convective clouds as simulated in an axisymmetric model with detailed microphysics, 1. Description of the model, J. Atmos. Sci., 53, 497-519, 1996.

Rogers, D. C.: Aggregation of natural ice crystals, Wyoming Univ., Laramie, Dept. of Atmospheric Resources, Report AR110, 3535, 1974.

Rosenfeld, D. and Woodley, W. L.: Deep convective clouds with sustained supercooled liquid water down to $-37.5^{\circ} \mathrm{C}$, Nature, 405, 440-442, 2000.

Rutledge, S. A. and Hobbs, P. V.: The Mesoscale and Microscale Structure and Organization of Clouds and Precipitation in Midlatitude Cyclones, XII: A Diagnostic Modeling Study of Precipitation Development in Narrow Cold-Frontal Rainbands, J. Atmos. Sci., 41, 2949-2972, 1984.

Sasyo, Y. and Tokuue, H.: The Collection Efficiency of Simulated Snow Particles for Water Droplets (Preliminary Report), Pap. Meteorol. Geophys., 24, 1-12, 1973.

Schlamp, R. J., Pruppacher, H. R., and Hamielec, A. E.: A Numerical Investigation of the Efficiency with which Simple Columnar Ice Crystals Collide with Supercooled Water Drops, J. Atmos. Sci., 32, 2330-2337, 1975.

Shupe, M. D., Matrosov, S. Y., and Uttal, T.: Arctic mixed-phase cloud properties derived from surface-based sensors at SHEBA, J. Atmos. Sci., 63, 697-711, 2006.

Takahashi, T. and Fukuta, N.: Supercooled Cloud Tunnel Studies on the Growth of Snow Crystals between -4 and $-20^{\circ} \mathrm{C}$, J. Meteorol. Soc. Jpn., 66, 841-855, 1988.

von Blohn, N., Diehl, K., Mitra, S. K., and Borrmann, S.: Riming of Graupel: Wind Tunnel Investigations of Collection Kernels and Growth Regimes, J. Atmos. Sci., 66, 2359-2366, 2009.

Wang, P. K. and Ji, W. S.: Collision efficiencies of ice crystals at low-intermediate Reynolds numbers colliding with supercooled cloud droplets: A numerical study, J. Atmos. Sci., 57, 10011009, 2000.

Zhang, D., Wang, Z., Heymsfield, A., Fan, J., and Luo, T.: Ice Concentration Retrieval in Stratiform Mixed-Phase Clouds Using Cloud Radar Reflectivity Measurements and 1D Ice Growth Model Simulations, J. Atmos. Sci., 71, 3613-3635, 2014. 